OPEN ACCESS

Edited by:

Serge Benichou,

Centre National de la Recherche Scientifique (CNRS), France

Reviewed by:

Lucie Bracq,

Institut Pasteur of Shanghai (CAS),

China

Jan Rehwinkel,

University of Oxford, United Kingdom

*Correspondence:

Julia G. Prado

jgarciaprado@irsicaixa.es

Specialty section:

This article was submitted to

Viral Immunology,

a section of the journal

Frontiers in Immunology

Received: 09 October 2018 Accepted: 22 November 2018 Published: 06 December 2018

Citation:

Colomer-Lluch M, Ruiz A, Moris A and Prado JG (2018) Restriction Factors: From Intrinsic Viral Restriction to Shaping Cellular Immunity Against HIV-1. Front. Immunol. 9:2876 doi: $10.3389 /$ fimmu.2018.02876

\section{Restriction Factors: From Intrinsic Viral Restriction to Shaping Cellular Immunity Against HIV-1}

\author{
Marta Colomer-Lluch ${ }^{1}$, Alba Ruiz ${ }^{1}$, Arnaud Moris ${ }^{2}$ and Julia G. Prado ${ }^{1 *}$ \\ ${ }^{1}$ IrsiCaixa AIDS Research Institute, Germans Trias i Pujol Research Institute, Universitat Autonoma de Barcelona, Badalona, \\ Spain, ${ }^{2}$ Sorbonne Université, INSERM U1135, CNRS ERL 8255, Centre d'Immunologie et des Maladies Infectieuses \\ (CIMI-Paris), Paris, France
}

Antiviral restriction factors are host cellular proteins that constitute a first line of defense blocking viral replication and propagation. In addition to interfering at critical steps of the viral replication cycle, some restriction factors also act as innate sensors triggering innate responses against infections. Accumulating evidence suggests an additional role for restriction factors in promoting antiviral cellular immunity to combat viruses. Here, we review the recent progress in our understanding on how restriction factors, particularly APOBEC3G, SAMHD1, Tetherin, and TRIM5 $\alpha$ have the cell-autonomous potential to induce cellular resistance against HIV-1 while promoting antiviral innate and adaptive immune responses. Also, we provide an overview of how these restriction factors may connect with protein degradation pathways to modulate anti-HIV-1 cellular immune responses, and we summarize the potential of restriction factors-based therapeutics. This review brings a global perspective on the influence of restrictions factors in intrinsic, innate, and also adaptive antiviral immunity opening up novel research avenues for therapeutic strategies in the fields of drug discovery, gene therapy, and vaccines to control viral infections.

Keywords: restriction factors, HIV-1, innate immunity, adaptive immunity, virus, degradation pathways, immunotherapies

\section{INTRODUCTION}

Restriction factors are host cellular proteins contributing to the frontline defense against viral infections. Restriction factors recognize and interfere with specific steps of the replication cycle of viruses, thereby blocking infection. They are generally interferon (IFN)-inducible and their inherent features, such as constitutive expression in different cell types, self-sufficient activity, and rapidity of action, confer a potent and early restriction of viruses (1). So far, more than nine groups of cellular restriction factors have been identified that inhibit Human Immunodeficiency Virus type 1 (HIV-1), and other primate lentiviruses, including the classical and well-documented APOBEC3G, SAMHD1, Tetherin/BST-2, and TRIM5 $\alpha(2-10)$, and those of more recent characterization MX-2, SERINC3/5, IFITMs, Schlafen 11, and MARCH2/8 (11-16). The continuous adaptation of HIV- 1 to the pressure exerted by the antiviral activities of restriction factors underscores the importance of restriction factors in controlling viral infections.

A tight regulation of innate and adaptive immune responses is required to counteract infections. During the acute phase of viral infections, pro-inflammatory cytokine storms contribute 
to controlling viral replication. These cytokine secretions are initiated in response to pattern recognition receptor (PRR) engagement by viral molecules (or pathogen-associated molecular patterns, PAMPs) and the recruitment at the site of entry of innate immune cells including natural killer (NK) cells, macrophages, dendritic cells (DCs), and other phagocytic cells. Innate immune cells, especially DCs, further orchestrate the priming of cells involved in adaptive immunity, meaning CD4+ T helper cells, CD8+ cytotoxic T lymphocytes (CTLs), and B cells (17). In particular, during HIV-1 infection, a robust CTL response has been linked to a reduction of HIV-1 viral loads and a delay in disease progression (18-26).

Beyond their intrinsic antiviral activity, recent evidence demonstrates that several restriction factors also participate in the modulation of HIV-1-specific cellular adaptive immunity, highlighting the multifaceted nature of these proteins. The connections of restriction factors with the cellular degradation machinery and its pathways suggest that common mechanisms might be shared by restriction factors to promote anti-HIV-1 cellular immunity. Here, we provide an overview of the cellintrinsic HIV-1 restriction activity of APOBEC3G, SAMHD1, Tetherin, and TRIM5 $\alpha$ proteins, focusing on their complex interplay with innate and adaptive immune responses in the context of HIV-1 infection. Besides, we briefly comment on the potential of a similar interplay in the case of more recently discovered anti-HIV-1 factors. In our view, a better understanding of the molecular interactions between restriction factors, viruses, and the protein degradation machinery might help in developing novel therapeutic strategies to enhance innate and adaptive immune responses against viral infections such as HIV-1.

\section{RESTRICTION FACTORS: INTRINSIC ANTIVIRAL ACTIVITY AND MODULATION OF INNATE AND ADAPTIVE IMMUNITY}

\section{APOBEC3G}

APOBEC3G (A3G) proteins belong to the AID/APOBEC family (apolipoprotein B mRNA editing enzyme, catalytic polypeptidelike) of cytidine deaminase enzymes. AID/APOBEC family members restrict a broad range of viruses including hepatitis $B$ virus (HBV) as well as endogenous and pathogenic retroviruses (27-30). Interestingly, it was the interaction of the HIV-1 accessory protein Vif with A3G that led to the identification of A3G as a restriction factor (31). Upon HIV-1 infection, A3G and other APOBEC family members, such as APOBEC3F (A3F), are encapsidated into budding virions. In newly infected cells, during the reverse transcription of the viral RNA, A3G and A3F catalyze cytosine-to-uracil deamination in the nascent viral DNA. As a consequence, the proviral DNA harbors a high frequency of G-to-A hypermutations leading to the introduction of amino acid substitutions and premature STOP codons. Transcriptional activation of $\mathrm{A} 3 \mathrm{G}$-edited provirus yields to the production of defective proteins and non-functional viral particles, resulting in a strong inhibition of $\mathrm{HIV}-1$ replication $(7,8,32)$. Although the capacity to inflict G-to-A mutations has been considered as the central mechanism of A3G- and A3F-mediated restriction, $\mathrm{A} 3 \mathrm{G}$ and $\mathrm{A} 3 \mathrm{~F}$ also exert deaminase-independent viral restriction $(33,34)$.

The HIV-1 Vif protein has evolved to antagonize A3G antiviral activity as well as other APOBEC family members that restrict viral infection $(34,35)$. In brief, Vif binds to A3G promoting the recruitment of the ElonginB/C-Cullin-5 E3 ubiquitin ligase complex leading to $A 3 G$ poly-ubiquitination and proteasomal degradation, which results in a lower rate of $A 3 G$ incorporation within the newly produced virions (36-38).

A3G is the most well-defined anti-HIV-1 protein of the APOBEC3 (A3) group. In humans, the A3 group consists of seven enzymes largely distributed in different cells and tissues, which contribute to DNA/RNA metabolism and cellular maintenance through their DNA/RNA deamination activities $(32,39,40)$. Specifically, A3G and A3F are highly abundant in multiple cell types (41), but their expression in immune cells, predominantly in activated $\mathrm{T}$ cells, monocytes, macrophages, and mature DCs, strongly suggests that $\mathrm{A} 3 \mathrm{G}$ and $\mathrm{A} 3 \mathrm{~F}$ exert diverse functions in immunity (42). On the one hand, various inflammation mediators like IFN- $\alpha$ increase A3G expression in monocytes, macrophages, and plasmacytoid dendritic cells (pDCs), while IFN- $\gamma$ and IFN- $\beta$ enhance A3G expression in macrophages (41, $43,44)$, indicating that $\mathrm{A} 3 \mathrm{G}$ and $\mathrm{A} 3 \mathrm{~F}$ are encoded by IFNstimulated genes and suggesting that these enzymes play a central role in innate antiviral immunity. In fact, the expression of A3G is induced by pathogen sensors such as Toll-like receptors (TLRs), as well as by cytokines such as IL-2, IL-7, IL-15, and IL-27 (45).

On the other hand, A3G itself also promotes innate and adaptive immunity. In particular, A3G-mediated cytidine deamination is sensed by the cellular DNA repair machinery driving the induction of stress responses and the activation of NK cells (46). Also, mouse APOBEC3 (mA3) was reported to act as a modulator of adaptive immunity eliciting both CTL responses and the generation of neutralizing antibodies (nAbs) against Friend retrovirus infection (47-49). However, how mA3 exacerbates CTL and nAbs production is not well-defined. In human cells, Casartelli et al. demonstrated that the editing activity of A3G favors the generation of HIV-1 antigenic peptides (epitopes) by infected cells leading to enhanced activation of HIV-1-specific CTL responses (50). In brief, in CD4+ T cells, the A3G-mediated HIV-1 restriction was associated with enhanced activation of HIV-1-specific CTL responses. The mechanism proved to be dependent on the A3G-mediated editing of the viral genome since $\mathrm{A} 3 \mathrm{G}$ mutants with impaired editing activity failed to induce CTL activation. Furthermore, introducing a premature STOP codon in HIV-1 genome, mimicking A3G editing, led to higher CTL activation most likely due to the generation of additional viral epitopes processed by proteasomes and presented by MHC class-I (MHC-I) molecules $(50,51)$ (Figure 1). These results were further corroborated in the context of A3G (and $\mathrm{A} 3 \mathrm{~F}$ ) expression in DCs and CTL activation, suggesting that in infected DCs, A3G- and A3F-mediated editing of viral genomes might enhance the capacity of DCs to prime antiviral CTL responses (52). Interestingly, although A3G editing activities can positively influence CTL activation, they can also negatively affect CTL responses by aiding to the emergence of CTL escape 


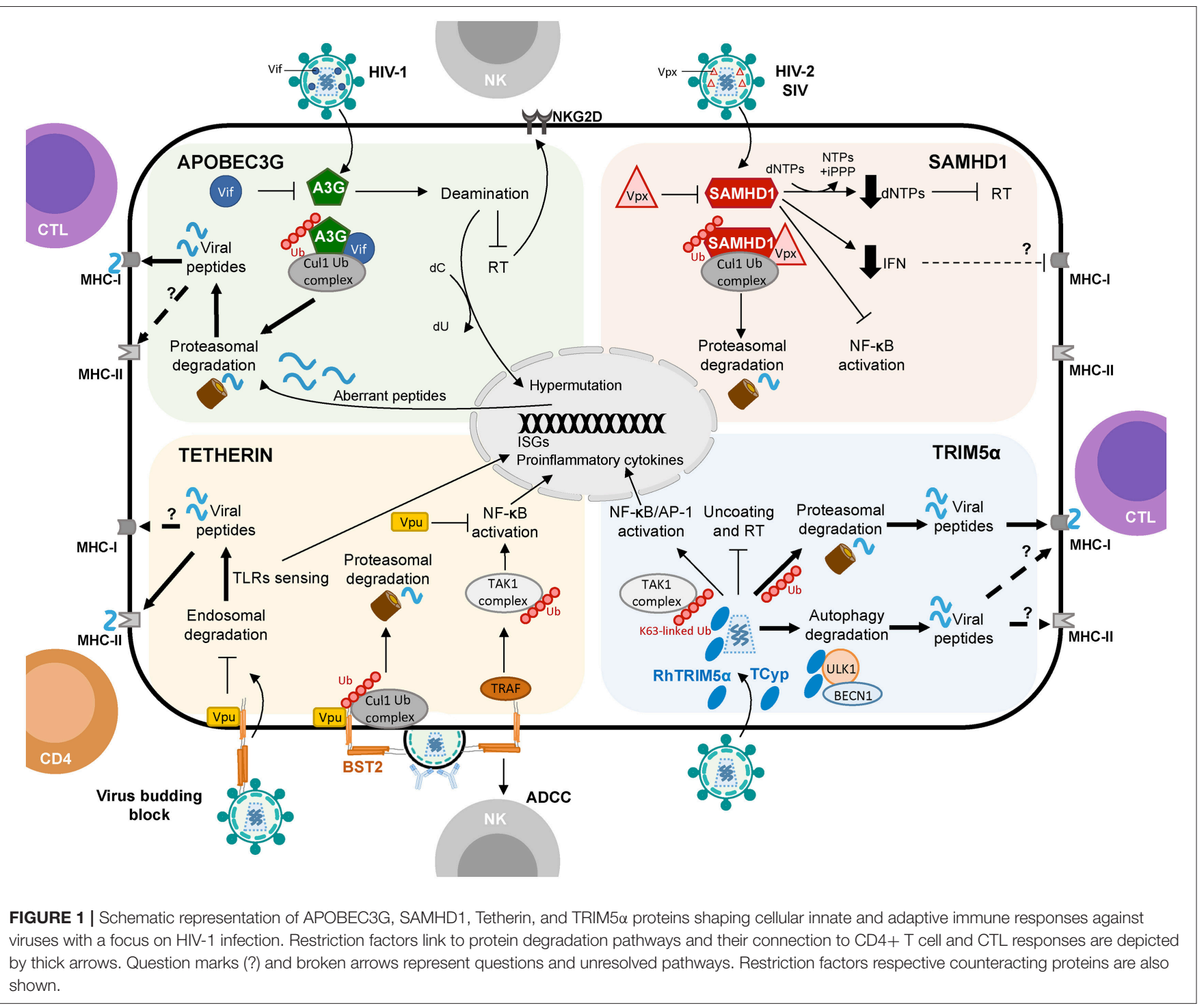

mutations $(53,54)$. The A3G-mediated effect on HIV-1 epitope presentation to CTLs appears to be beneficial or detrimental depending on the HLA allotype of the subject (55). Thus, a precise calibration between A3G-derived antigen generation and incorporation of epitope mutational changes is fundamental to contribute to the activation of specific CTL responses against HIV-1 infected cells via A3G. Remarkably, in patients under effective antiretroviral treatment, CTL recognition of epitopes derived from A3G-mediated mutated polypeptides and expressed by defective proviruses probably shapes the repertoire of latently infected cells (56).

Interestingly, studies of $\mathrm{A} 3 \mathrm{G}$ in rhesus macaques revealed that upon immunization with SIV antigens and CCR5 peptides linked to the HSP70 protein there was a progressive increase in $\mathrm{A} 3 \mathrm{G}$ expression in memory CD4 $+\mathrm{T}$ cells $(57,58)$, eliciting protection against the virus through induction of innate and adaptive immunity. Similarly, immunization of rhesus macaques with recombinant HLA constructs, linked with HIV-1 and SIV antigens and HSP70, resulted in upregulation of A3G in CD27+ memory B cells (59), which might be associated with a protective effect against infection. In humans, B cells express A3G that has been postulated to be transmitted via exosomes to targets of HIV-1 infection to exert its antiviral activity $(31,32,60)$.

\section{SAMHD1}

SAMHD1 (Sterile Alpha Motif and Histidine Aspartate domaincontaining protein 1) is a deoxynucleotide triphosphohydrolase that impairs HIV-1 reverse transcription by reducing the pool of cellular dNTPs $(5,61,62)$. Upon HIV-1 infection of CD4+ T cells, the HIV-1 capsid is delivered into the cytoplasm allowing reverse transcription of the viral RNA into DNA, a step that is strictly dependent on the availability of the dNTPs. SAMHD1 hydrolyzes all four dNTPs to deoxynucleosides and inorganic triphosphate thus controlling the pool of cytosolic dNTPs. As a consequence, in myeloid cells, SAMHD1 prevents proviral DNA formation and HIV-1 replication (4-6). In addition to its 
dNTPase activity, SAMHD1 also exhibits an RNase activity that might as well participate in SAMHD1-mediated viral restriction, for instance by targeting viral RNA for degradation before RT occurs $(63,64)$. However, to what extent this RNase activity contributes to HIV-1 restriction remains an open question (63, $65,66)$.

HIV-2 and certain simian immunodeficiency virus strains (SIV sm/SIVmac) encode an accessory protein, Vpx, to overcome SAMHD1 restriction (67). Vpx interacts with the C-terminal domain of SAMHD1 recruiting the Cullin-4 E3 ubiquitin ligase complex, which destines SAMHD1 for poly-ubiquitination and proteasomal degradation thus relieving SAMHD1-mediated retroviral blockade $(4,6,68)$. While Vpx from HIV-2 and most SIVs efficiently oppose SAMHD-1, HIV-1 and its simian ancestor infecting chimpanzees (SIVcpz) lack Vpx and are unable to counteract SAMHD1 and are vulnerable to its action (4).

Some myeloid cells-monocytes, macrophages, and DCsand CD4+ T cells ubiquitously express SAMHD1 $(4,6,69)$, which regulates their cell cycle by controlling the availability of the dNTP pools. Apart from being the substrates of SAMHD1, dNTPs, mainly driven by the levels of dGTP, globally regulate and equilibrate SAMHD1 structural states (61). However, the high expression levels of SAMHD1 both in cells refractory to HIV-1 such as monocytes and quiescent lymphocytes, or in cells permissive to HIV-1 such as macrophages and activated lymphocytes, argues for a posttranslational regulation of SAMHD1 functions $(70,71)$. Indeed, the Cyclin-dependent kinase 6 (CDK6) coupled with cyclin D3 was shown to control CDK2-dependent SAMHD1 phosphorylation in proliferating cells $(72,73)$. The phosphorylation of SAMHD1 alleviates its capacity to hydrolyze dNTPs controlling the availability of dNTPs for cellular DNA synthesis during the cell cycle and reverse transcription of the viral RNA (72).

Given its ability to limit the intracellular dNTP pool, SAMHD1 is tightly linked to the mechanisms of cell-cycle progression, as dNTPs availability is crucial for cycling cells. In addition, SAMHD1 may avoid the accumulation of nucleotides that otherwise would trigger innate immune sensing leading to undesired IFN-I secretion and chronic inflammation (66). In fact, deficiency in SAMHD1 leads to increased IFN production, upon viral DNA sensing by cGAS, and innate immune activation causing autoimmune disorders in patients (74). This is illustrated by mutations in SAMHD1 described as the cause of some cases of the Aicardi-Goutières syndrome, a rare autoimmune disease characterized by an IFN-stimulated gene expression signature that resembles a congenital viral infection and overlaps clinically and biochemically with the systemic lupus erythematosus (75). Recently, Chen and colleagues also suggested that SAMHD1 may act as a negative regulator of the cell-intrinsic antiviral responses (76). They described, in vitro and in vivo, how SAMHD1 down-regulates innate antiviral immune responses and inflammation by actively inhibiting NF- $\mathrm{B}$ activation (by reducing the phosphorylation of $\mathrm{I} \kappa \mathrm{B} \alpha$ ) and IFN-I induction (by reducing IKK $\varepsilon$-mediated IRF7 phosphorylation).

Owing to the inefficient capacity of HIV-1 to infect DCs, mainly due to the restriction exerted by SAMHD1, it has been proposed that HIV-1 might evade innate sensing $(4,77)$. In this context, it has been shown that lentiviral transduction of SAMHD1 in myeloid cells prevents the induction of IFN responses as well as antigen presentation (78). The blockage of HIV-1 by SAMHD1 might lower the capacity of DCs and macrophages to detect cytosolic viral DNA preventing the activation of the cGAS/STING pathway for IFN production and innate antiviral immunity. Hence, SAMHD1 negative regulation of the innate immune response would be used by HIV-1 as a mechanism to bypass host innate immunity (66). However, this function of SAMHD1 is rather indirect and numerous reports demonstrated that HIV-1-infected DCs exhibit an intermediate maturation phenotype, suggesting that HIV-1 cryptic replication in DCs is sensed and engages intrinsic innate immune responses $(52,77,79)$.

Few studies have addressed the potential role of SAMHD1 in connecting innate and adaptive immune responses in HIV-1 infection. Ayinde et al. evaluated the contribution of SAMHD1 in HIV-1 antigen presentation via MHC-I molecules by monocytederived DCs (80). The authors demonstrated that SAMHD1 antiviral activity hampers $\mathrm{HIV}-1$ replication while Vpx-mediated depletion of SAMHD1 augments the presentation of viral antigens by DCs, which leads to the activation of HIV-1specific CTL responses and the killing of infected DCs (80) (Figure 1). Similarly, SAMHD1 retroviral restriction has been associated with defects in virus-specific CD8 $+\mathrm{T}$ cell responses in a lentiviral-infected mice model (78).

Several studies suggested that SAMHD1 may play a role in HIV-1 pathogenesis and disease progression, albeit conclusive evidence of a protective role are still lacking. While some authors described an association between the reduction of SAMHD1 activity in DCs with the capacity to naturally suppress viral replication in the absence of antiretroviral treatment (in so-called elite controllers) (81), others reported an up-regulation (82) or absence of differences in SAMHD1 expression levels in elite controllers as compared to control groups (83).

Nonetheless, it is interesting to note that SAMHD1 restriction activity might compete with the activation of innate and adaptive immune responses. This is in agreement with observations in autoimmune diseases and cancer where deregulation of dNTP levels and defects in nucleic acids metabolism impair cellular viability and trigger chronic stimulation of innate immune responses [reviewed in (66)].

\section{Tetherin/BST-2}

Tetherin/BST-2 (Bone marrow stromal antigen 2) is an IFNinducible transmembrane protein that potently anchors budding viral particles on the surface of infected cells, preventing the release of HIV-1 and other enveloped viruses $(9,10)$. This function is achieved by Tetherin's unique topology, with the presence of an N-terminal transmembrane domain and a Cterminal glycosyl-phosphatidylinositol group, which allows one end of the protein to be attached to the plasma membrane and the other to the viral envelope. The retained virions are then internalized and degraded via the endosomal/lysosomal pathway $(84,85)$.

Tetherin exerts antiviral activity against a broad spectrum of enveloped viruses. However, primate lentiviruses have 
evolved three different viral proteins to escape Tetherin restriction in a species-specific manner. The HIV-1 Vpu protein overcomes human Tetherin restriction by (i) promoting the poly-ubiquitination of its transmembrane domain inducing its proteasomal degradation, (ii) downregulating Tetherin's concentration on the cell surface, and (iii) sequestering Tetherin in endosomal compartments leading to its lysosomal degradation via a non-canonical autophagy dependent pathway $(10,86-$ 92). In contrast, in HIV-2 the Env protein circumvents human Tetherin (93). In the case of most SIVs, the Nef protein targets a five amino acid sequence in the $\mathrm{N}$-terminal cytoplasmic domain promoting simian Tetherin endocytosis and lysosomal degradation (94-96). Interestingly, human Tetherin lacks this five amino acid region conferring resistance to Nef antagonism.

Upon viral infection, most immune cells upregulate Tetherin expression, which has a short and a long isoform. The short isoform of Tetherin lacks 12 residues in its cytoplasmic tail and is resistant to Vpu-driven counteraction. Meanwhile, the longer version has been linked to the activation of the NF$\kappa \mathrm{B}$ pro-inflammatory signaling cascade $(97,98)$. In fact, the accumulation of tethered virions at the plasma membrane results in the activation of the NF- $\kappa \mathrm{B}$ signaling pathway with the subsequent induction of pro-inflammatory responses (99-101), unveiling Tetherin's additional function as a viral sensor in innate immunity beyond its direct restriction activity. Note that Vpu abrogates Tetherin-mediated NF-kB activation (102). In addition, Tetherin seems to be involved as a negative regulator of innate immunity through an interaction with the immunoglobulin-like transcript 7 (ILT7) inhibitory receptor. In pDCs, the interaction of Tetherin with ILT7 impairs TLR signaling inhibiting IFN-I and proinflammatory cytokine production $(103,104)$.

Interestingly, Arias et al. elegantly demonstrated that Tetherin enhances the susceptibility of HIV-1 infected cells to antibody-dependent cellular cytotoxicity (ADCC) by introducing mutations in $\mathrm{Vpu}$ that prevent Tetherin antagonism. Consistently, RNA silencing of Tetherin expression decreased the susceptibility of HIV-1-infected cells to ADCC (105) (Figure 1). Remarkably, overexpression of BST-2 in response to IFN- $\alpha$, but also to IFN- $\beta$ and IL-27 that upregulate Env expression at the cell surface, sensitizes HIV-1-infected cells to elimination by ADCC (106). Thus, a Tetherin-mediated increased sensitivity of HIV-1-infected cells to ADCC may serve as a link between innate and adaptive immunity to augment the susceptibility of virus-infected cells to antibodies, with the potential to enhance other immune responses to control viral replication in vivo.

It has been proposed that Tetherin-mediated virus internalization might feed TLR containing compartments with viral PAMPs, thus enhancing TLR activation (107) but also providing antigens to compartments rich in MHC class-II (MHC-II) molecules leading to antigen presentation of viral peptides, thus affecting both innate and adaptive immune responses. In line with this hypothesis, Li et al. provided evidence that Tetherin promotes NK cell, and virus-specific CD4+ and $\mathrm{CD} 8+\mathrm{T}$ cell responses in a mouse model of Friend retrovirus infection (108). Tetherin knockout mice showed weaker antiviral responses compared to wild-type mice exemplified by a decrease in IFN- $\gamma$ production by NK cells, CD4+ and CD8+ T cells (108). Indeed, Tetherin activity might improve DCs activation and MHC-II antigen presentation in acute retroviral infection in vivo (109). These findings further support the idea that Tetherin not only functions as a restriction factor but also as a modulator of cellular-mediated immunity against retroviruses. Although the exact underlying molecular mechanism remains to be elucidated, the authors propose that Tetherin promotes the endocytosis and degradation of tethered viruses to induce an effective antiviral cellular immune response (109) (Figure 1). However, whether Tetherin-mediated virion endocytosis directly drives HIV-1 antigen degradation and presentation remains to be determined.

\section{TRIM5 $\alpha$}

Tripartite motif (TRIM) proteins constitute a large family of E3 ligases-with approximately 100 known TRIM genes in humans (110)_implicated in many cellular processes including cell differentiation, apoptosis, autophagy, carcinogenesis, antiviral immunity, and innate signaling (111-114). TRIM proteins are defined by an N-terminal RBCC structure, which consists of an N-terminal RING E3 ligase domain (R), one or two Bbox domains (B), and a coiled-coil domain (CC). Following the RBCC feature, the C-terminal domain(s) clusters the TRIM proteins into subgroups, with the PRYSPRY (or B30.2) domain being the most frequently found C-terminal domain among TRIM family members. Importantly, the PRYSPRY domain is responsible for the binding to the retroviral capsid and determines the spectrum of retroviral restriction (115-117).

Several TRIM family members have antiretroviral activity (114, 118), amongst which the TRIM5 gene exhibits one of the strongest signatures of positive selection in the human genome as a marker of antagonistic virus-host coevolution and antiviral potency (1). The isoform $\alpha$ of TRIM5 (TRIM5 $\alpha$ ) displays the most potent antiviral activity and a large crossspecies recognition pattern that underpins its importance in the control of primate lentiviral infections $(2,119)$. Of note, deletion or mutation of the TRIM5 $\alpha$ RING domain impairs TRIM5 $\alpha$ capacity to restrict viral infections $(120,121)$. TRIM $5 \alpha$ is a cytosolic protein that functions in a cell-type specific manner (122-124) and inhibits retroviral replication in a species-specific fashion $(115,116,122)$. For instance, TRIM5 $\alpha$ proteins from Old World monkeys, such as rhesus macaques, restrict a broad range of retroviruses including HIV-1, HIV-2, N-tropic murine leukemia virus (N-MLV), and equine infectious anemia virus (EIAV). Nevertheless, they are ineffective against infection with certain SIV strains ( SIV $\left._{\text {mac }}\right)$ $(2,125)$. Meanwhile, New World monkeys TRIM5 $\alpha$ proteins do not generally suppress HIV-1. The exception is found in New World owl monkeys where the PRYSPRY domain of TRIM5 $\alpha$ has been replaced by a cyclophilin A binding domain (TRIMCypA) that hampers HIV-1 infection very vigorously $(113,119,126,127)$. It is widely assumed that human TRIM5 $\alpha$ (hTRIM5 $\alpha$ ) is unable to efficiently restrict HIV-1 although it strongly restricts N-MLV and EIAV (2, 125, 128, 129). However, recent studies indicate that changes in hTRIM5 $\alpha$ expression levels and some genetic polymorphisms may influence the 
susceptibility to HIV-1 infection in human cells $(122,130-$ $135)$, and may be associated with slow disease progression $(133,134,136)$. Moreover, some primary HIV-1 clinical isolates harboring capsid mutations in response to $\mathrm{CD} 8+\mathrm{T}$ cell pressure have been reported to be more sensitive to hTRIM5 $\alpha$ inhibition compared to HIV-1 laboratory-adapted strains (137). Interestingly, it has been proposed that C-type-lectin-receptordependent uptake of HIV-1 might control the restriction by hTRIM $5 \alpha$, dictating protection or infection of human DCs subsets (122).

TRIM5 $\alpha$ mediates its antiviral function through complementary activities, even though some of the mechanistic details remain to be elucidated. As a restriction factor, TRIM5 $\alpha$ directly binds to the incoming retroviral capsid through its PRYSPRY domain, driving the premature uncoating of HIV-1 and impairing reverse transcription and genome translocation to the nucleus, thereby abrogating retroviral integration $(2,3,138-$ 140). This process requires the assembly of TRIM5 $\alpha$ dimeric and multimeric structures with the HIV-1 p24 protein hexamers that constitute the capsid lattice (141-144). In addition, some authors suggest that the proteasomal machinery recruited via the TRIM5 $\alpha$ E3 ubiquitin ligase activity may block retroviral replication (145-148). As Tetherin, TRIM5 $\alpha$ may also act as a viral sensor by recognizing the HIV-1 retroviral capsid. TRIM5 $\alpha$ binding to a susceptible retroviral capsid increases its E3 ubiquitin ligase activity, which catalyzes the synthesis of unanchored K63-linked poly-ubiquitin chains that activate the TAK1 kinase protein leading to downstream activation of AP-1- and NF-кB-dependent cascades (149-152), which may lead to the modulation of innate and adaptive immune responses. Although TRIMCypA lacks the PRYSPRY domain, it also activates the TAK1 pathway (149), suggesting that the E3 ubiquitin ligase activity (RING domain) is crucial for TRIM $5 \alpha$ mediated immune signaling. Indeed, several reports highlight the regulation of innate immunity by multiple TRIM proteins $(153,154)$.

Evolution studies of TRIM orthologs in various species revealed a remarkable paralleled co-evolution of genes encoding TRIM proteins and the development of the innate and adaptive immune systems $(153,155)$. This phenomenon may be indicative of a role of TRIM proteins in innate immunity and, directly or indirectly, in the establishment of the adaptive immune responses (153). Interestingly, in immune cells, mRNA expression profile studies of TRIMs led to the identification of fifteen TRIM proteins expressed at high levels in $T$ and/or B cells (153). Similarly, the expression of a specific subgroup of TRIM genes was significantly upregulated in CD4+ T cells compared to macrophages and DCs (124). In a mouse model, deletion of TRIM30-the mouse homolog of hTRIM $5 \alpha$-enhanced the CD4+/CD8 $+\mathrm{T}$ cell ratio and, upon TCR activation, reduced NF- $\kappa$ B activation and IL-2 production in $\mathrm{CD} 4+\mathrm{T}$ cells compared to wild-type mice (156). These data suggest that TRIM30 operates via the NF$\mathrm{kB}$ pathway as a modulator of $\mathrm{CD} 4+\mathrm{T}$ cells function. Notably, we recently showed that rhesus TRIM5 $\alpha$ (rhTRIM5 $\alpha$ ) and TRIMCypA expression in HIV-1-infected cells leads to enhanced recognition and killing of infected cells by $\mathrm{CD} 8+\mathrm{T}$ cells
(157) (Figure 1). Our results strongly indicate that non-human TRIM5 $\alpha$ variants play a role in restriction and increase CTL activation linking innate and adaptive immune responses in HIV-1 infection.

\section{Recently Discovered Restriction Factors}

Although limited information is available, the possibility that recently discovered restriction factors may play a role in antiviral cellular immunity beyond viral restriction should not be excluded and be worth exploring.

In the case of the MARCH8 and MARCH2 (MembraneAssociated RING-CH 8 or 2 proteins) E3 ubiquitin ligases their enzymatic activity is critical for their antiviral function. These factors drive Env down-regulation from the plasma membrane and its intracellular sequestration to decrease Env incorporation into newly produced HIV-1 virions (15). In addition, MARCH2 was found to be upregulated upon HIV-1 infection in Jurkat and THP-1 cells promoting Env ubiquitination and its subsequent lysosomal degradation (16). These observations suggest a possible activity for MARCH2 in redirecting Env glycoproteins via the lysosomal route to antigen presentation pathways. Another example could be found in IFITMs (Interferon-inducible transmembrane proteins). IFITMs are small membrane-associated cellular factors that inhibit the replication of HIV-1 and other enveloped viruses at the entry step (13). IFITMs do not block the internalization of viruses but rather the virus-cell fusion process. Despite recent progress, the fate of incoming virions and the mechanistic details of IFITMs antiviral activity remain elusive. However, since IFITMs are localized in endosomes and lysosomes, it is tempting to speculate that they might be involved in targeting viruses for vesicular degradation and MHC-II loading. Indeed, the N-terminal domain of IFITM3 contains a Tyrosine Motif responsible for its endocytosis and localization in endocytic vesicles and lysosomes (158); meanwhile, the C-terminal motif of IFITM1 favors its localization in LAMP1-positive lysosomes (159). Remarkably, using the murine CMV (MCMV) model of infection, it has been shown that although IFITM3 does not restrict MCMV replication, IFITM3 deficiency leads to an impairment of cellular immunity most likely due to an unbalanced release of cytokines that drive lymphopenia including NK cell death and T cells depletion (160). Besides, in the course of influenza virus infection in mouse, IFITM3 expression in lung resident memory CD8+ T cells facilitated their survival and protection from viral infection during subsequent exposures (161). Overall, whether IFITMs also tag HIV-1 and other viruses to degradation and viral antigens production for antigen presentation and activation of $\mathrm{T}$ cells remains to be determined. Further insights may improve our understanding of these less characterized restriction factors, and others such us MX-2, SERINC3/5, and Schlafen 11, and their plausible function in the activation of antiviral cellular immunity.

Taken together, restriction factors may participate in shaping antiviral immunity working as a link between intrinsic cellular defenses of innate immunity and adaptive immune responses to control HIV-1 infection (Table 1 and Figure 1). Accumulating evidence suggests a connection between restriction factors and 
TABLE 1 | Restriction factors and their impact on antiviral cellular immunity.

\begin{tabular}{|c|c|c|c|}
\hline $\begin{array}{l}\text { Restriction } \\
\text { factor }\end{array}$ & Impact on antiviral cellular immunity & Virus & References \\
\hline \multirow[t]{3}{*}{ APOBEC3G } & $\begin{array}{l}\text { Enhances the recognition of HIV-1 infected T cells by NK cells through upregulation of } \\
\text { NKG2D-activating ligands }\end{array}$ & HIV-1 & $(46)$ \\
\hline & Enhances the ability of HIV-1 infected T cells to activate CTL recognition & HIV-1 & $(50)$ \\
\hline & Increases the production of MHC-I viral antigens in DCs favoring CTL activation & & $(52)$ \\
\hline \multirow[t]{3}{*}{ SAMHD1 } & $\begin{array}{l}\text { Vpx-mediated SAMHD1 depletion in HIV-1 infected DCs increases viral antigen } \\
\text { presentation leading to the activation of HIV-1-specific CTL responses }\end{array}$ & HIV-1 & (80) \\
\hline & Prevents virus-specific CD8+ T cell responses in vivo & Lentivirus & (78) \\
\hline & $\begin{array}{l}\text { Reduced induction of SAMHD1 in DCs from Elite Controllers induces HIV-1-specific } \\
\text { CTL responses }\end{array}$ & HIV-1 & $(81)$ \\
\hline \multirow[t]{3}{*}{ TETHERIN } & Enhances the susceptibility of HIV-infected cells to elimination by ADCC & HIV-1 & $(105,106)$ \\
\hline & $\begin{array}{l}\text { Promotes NK cell, CD4+ and CD8 }+ \text { T cell responses against retrovirus infection in } \\
\text { vivo }\end{array}$ & Friend retrovirus & $(108)$ \\
\hline & $\begin{array}{l}\text { Improves DCs activation and MHC class II antigen presentation via Tetherin-mediated } \\
\text { virion endocytosis }\end{array}$ & Friend retrovirus & $(109)$ \\
\hline TRIM5 $\alpha$ & rhTRIM5 $\alpha$ and TRIMCypA improve activation of HIV-1-specific CD8+ T cell responses & HIV-1 & $(157)$ \\
\hline
\end{tabular}

cellular degradation pathways such as the ubiquitin proteasome system, and the autophagy and endocytic routes, which may establish a framework to shape HIV-1-specific cellular immunity. In the following section, we will focus on recent studies suggesting a fine-tuned interplay between the four canonical restriction factors (A3G, SAMHD1, Tetherin, and TRIM5 $\alpha$ ) and the protein degradation pathways for the production of class I and class II viral antigens to activate HIV-1-specific T cell immunity.

\section{RESTRICTION FACTORS AND PROTEIN DEGRADATION PATHWAYS}

\section{The Ubiquitin-Proteasome System (UPS)}

The UPS participates in the ubiquitin-dependent, and occasionally independent, degradation of cellular proteins regulating antigen processing, transcriptional modulation, signal transduction, among other cellular processes (162). Notably, in the context of HIV-1 infection, the UPS aids in the degradation and removal of viral proteins. Also, the UPS enhances the ubiquitination of cellular factors that recognize viral structures allowing the formation of high molecular complexes directed for proteasomal degradation. Besides, the UPS contributes to the regulation of signaling molecules involved in the activation of innate immunity to combat the infection (163). However, it is well-known that HIV-1, as well as many other viruses, subvert the UPS machinery to favor viral replication and escape from host immune surveillance (163-165). Indeed, HIV-1 manipulates the UPS to: (i) increase viral protein expression levels, stability, and activities by posttranslational modifications such as ubiquitination; (ii) recruit cellular E3 ligases to redirect antiviral proteins for proteasomal degradation; and (iii) to suppress the expression of host antiviral genes by controlling the activity of cellular transcription factors such as AP-1, NF- $\mathrm{B}$, and STATs, among others $(68,163,166)$.

In general, in infected cells, proteins present in the cytoplasm are degraded by the UPS generating short peptides. These epitope precursors are then translocated in the endoplasmic reticulum (ER) through the action of a specific transporter associated with antigen processing (TAP) and further trimmed by ER-resident amino-peptidases to generate epitopes. These epitopes are loaded onto nascent MHC-I molecules to be displayed on the cell surface for their recognition by epitope-specific CD8+T cells. The connection between restriction factors and the UPS degradation machinery for cellular immunity is clearly exemplified by the A3G protein. A3G mediates G-to-A deamination in the HIV1 genome promoting the integration of hypermutated provirus. Although the resultant proviruses fail to produce novel infectious particles, they can express truncated or aberrant proteins that undergo UPS-dependent degradation providing epitopes for the loading of MHC-I molecules and contributing to the activation of HIV-1-specific CTLs (50) (Figure 1). These A3G-derived HIV-1 peptides constitute a previously unrecognized source of HIV1 antigens $(50,56)$. Numerous studies have characterized the involvement of the UPS in HIV-1 protein proteolysis and MHCI-restricted antigen presentation (51), for instance by targeting to degradation HIV-1 Env protein lacking the signal sequence for translocation to the ER (167) or ubiquitin-tagged HIV1 Nef and Gag proteins $(167,168)$. Remarkably, in HIV-1infected cells, following interactions with Vif, A3G is polyubiquitinated and hence constitute itself a substrate for UPSmediated degradation (38), providing as a consequence epitopes for MHC-I presentation. Indeed, A3G (and A3F)-specific CTL responses have been observed in both HIV-1-infected patients and SIV-infected rhesus macaques (169). Therefore, presentation of A3G-derived epitopes might also be a hallmark of HIV-1infected cells targeted by the adaptive immune response.

In the case of TRIM $5 \alpha$, as well as other TRIM family proteins, the UPS is essential for its antiviral activity, recruiting viral components for proteasomal-mediated degradation. TRIM5 $\alpha$ has E3 ubiquitin ligase activity and can be auto-ubiquitinated and rapidly degraded in a proteasome-dependent manner in the presence of retroviral cores $(147,170)$. Also, it has been shown that TRIM5 $\alpha$ interacts with the proteasome 
subunit PSMC2 and in infected cells co-localizes with a complex formed by proteasome subunits and HIV-1 (146, 171, 172). Intriguingly, although TRIM5 $\alpha$ contains a RING domain capable of ubiquitination and tagging viral proteins for proteasomal degradation, no TRIM $5 \alpha$-mediated ubiquitination of viral proteins has yet been detected. The functional link between restriction capacity and TRIM $5 \alpha$-directed proteasomal degradation was confirmed in the presence of proteasome inhibitors, which prevented the HIV-1-induced degradation of TRIM5 $\alpha$, blocked viral uncoating, and rescued HIV-1 reverse transcription. These observations support a model in which TRIM $5 \alpha$ restriction of incoming retroviral capsids may depend on the formation of a TRIM $5 \alpha$-viral protein complex promoting TRIM5 $\alpha$ autoubiquitination and delivery of the complex to the proteasome for degradation (147, 157, 173). Interestingly, it has been recently shown that several cellular deubiquitinatinginhibitors (DIs) enhance the poly-ubiquitination of Gag proteins and, consequently, increase Gag entry into the UPS and the MHC-I presentation pathway (174). This observation could lead to speculate that TRIM5 $\alpha$ proteins may recruit HIV-1 components to the UPS enhancing viral antigenic peptides' availability for MHC-I presentation and activation of CD8 $+\mathrm{T}$ cell responses (157) (Figure 1). On the other hand, TRIM5 $\alpha$, TRIM21, and TRIM25 poly-ubiquitination activities have been recently shown to bridge viral degradation with the activation of innate immunity $(149,175,176)$.

\section{The Autophagy Pathway}

Macroautophagy (commonly called autophagy) is a vesicular pathway of degradation that targets components residing in the cytoplasm, membranes, or nucleus for lysosomal degradation. As such, it contributes to the turnover of cytosolic organelles, lipids, and damaged or misfolded proteins. Interestingly, autophagy also modulates innate and adaptive immune responses (177-180). Indeed, autophagy regulates inflammatory responses by targeting for instance mitochondria and inflammasomes to lysosomal degradation (181). Pioneer work also revealed the implication of autophagy in the presentation of viral antigens, in particular by MHC-II molecules to CD4+ T cells (182-184). Additionally, autophagy contributes to the MHC-I-restricted presentation of nuclear antigens (185), primarily when viruses negatively interfere with the classical pathway of MHC-I presentation (186). Effectors of autophagy also participate in the recycling and trafficking of MHC-I molecules $(187,188)$.

Several studies demonstrated that TRIM protein family members are involved in the modulation of autophagy, both as regulators and receptors (189). For example, TRIM23 has been attributed to modulate the activity of central components of the autophagy process (190). In the context of TRIM $5 \alpha$, the impossibility to rescue viral infectivity in the presence of proteasome inhibitors $(138,145,147,148,170,176)$ suggests that the UPS might not be the only mechanism participating in the TRIM $5 \alpha$-mediated viral restriction process. In macrophages, it has been proposed that TRIM5 $\alpha$-mediated viral restriction relies on targeting viral capsids to autophagymediated degradation, involving direct interactions between HIV-1 viral capsid and effectors required for the formation of the autophagy initiation complex such as ULK1 and BECLIN1 (191-193). In Langerhans cells, TRIM5 $\alpha$ might mediate the assembly of an autophagy-activating complex targeting HIV1 for autophagy degradation and preventing the infection of these cells. Therefore, it is tempting to speculate that TRIM5 $\alpha$ interactions with HIV-1 could lead to autophagydependent processing of viral peptides and antigen presentation to $\mathrm{T}$ cells (Figure 1). Indeed, Blanchet et al. have shown that upon HIV-1 infection in human monocyte-derived DCs the incoming viral particles are at least partially degraded through an autophagy-dependent pathway leading to MHCII restricted presentation of $\mathrm{HIV}-1$ epitopes to $\mathrm{CD} 4+\mathrm{T}$ cells (194). In contrast, it is interesting to note that in HIV-1-infected DCs, autophagy does not contribute to the presentation of MHC-II restricted HIV-1 antigens derived from de novo synthesized viral proteins (195). Regardless, whether TRIM5 $\alpha$-mediated restriction feeds the autophagy-dependent antigen presentation pathway has not been investigated thus far. Also, note that in macrophages discordant results were reported showing no effect of the depletion of key autophagy effectors (Beclin1, ATG5, and p62) using siRNA or CRISPRCas9 knockout on hTRIM5 $\alpha$-, rhTRIM5 $\alpha$-, or TRIMCypAmediated restriction (196). These discrepancies potentially rely on the complementary or redundant roles played by the UPS and the autophagy machinery in protein degradation (197, 198). Therefore, it might be worth studying side by side the contribution of proteasome- and autophagy-mediated TRIM5 $\alpha$ retroviral restriction in various cell types.

\section{The Endo-Lysosomal System}

The endo-lysosomal system is comprised of early and late endosomes and lysosomes allowing the trafficking of plasma membrane components and macromolecules destined to lysosomal degradation. The endo-lysosomal pathway is essential for plasma membrane protein turnover and other cellular processes such as antigen presentation or receptor-mediated cell signaling. It relies on the internalization of endocytosed proteins that are initially transported to early endosomes. Then, these proteins are either recycled back to the plasma membrane and the trans-Golgi network or sequestered into early endosomes. Once early endosomes mature into late endosomes, in a process regulated by the ubiquitin ligase RING finger protein 26 (RNF26) (199), they fuse with lysosomes for cargo protein acidificationmediated degradation. Tagging proteins with ubiquitin also allows the direct internalization of proteins toward lysosomal degradation in a process mediated by the endosomal-sorting complex required for transport (ESCRTs)-machinery $(200,201)$.

In the case of Tetherin, its restriction activity leads to the accumulation of HIV-1 nascent virions at the cell membrane of infected cells. Intriguingly, the fate of tethered virions is not clear thus far. While some studies suggested that retained virions may trigger cell-to-cell spread (202), others contradicted these findings $(203,204)$. Of note, the N-terminal cytoplasmic tail of human Tetherin not only promotes the activation of the NF-kB signaling cascade but also serves as a binding site for clathrinmediated endocytosis and degradation of tethered virions (205). Based on this knowledge, work from $\mathrm{Li}$ et al. proposed a 
model where Tetherin-mediated endocytosis may induce specific cell-mediated immune responses against retroviral infection, although the exact mechanism is still unknown (109). Tetherin's restriction activity in retrovirally infected antigen presenting cells, such as macrophages and DCs, prevents the egress of virions from the plasma membrane. Since Tetherin's ability to enhance NK cell responses has been linked to its endocytic function, tethered virions in pDCs could be internalized in endosomes and recognized by TLR3 for the activation of NK cells (108). Moreover, the endo-lysosomal degradation of viral particles may result in increased viral peptide availability for MHC-II antigen presentation to activate $\mathrm{CD} 4+\mathrm{T}$ cell-mediated responses. This data would be in agreement with the mechanism observed in DCs, where DC-SIGN-mediated endocytosis of virions targets HIV-1 antigens to late endosomal/lysosomal compartments leading to MHC-II-restricted antigen presentation (206). In fact, ex vivo infected DCs from Tetherin wild-type mice display higher MHC-II expression and more potent stimulation of virus-specific CD4+ T cells, NK cells, and cytokine production compared to Tetherin knockout mice (207). Furthermore, Tetherin enhances $\mathrm{CD} 8+\mathrm{T}$ cell responses against Friend retrovirus infection in vivo by antigen cross-presentation to MHC-I (108) (Figure 1).

Overall, although it remains to be firmly established, a fine-tuned interplay between restriction factors and protein degradation pathways is probably of great benefit for both the initiation of innate and adaptive immune responses, in particular to promote viral antigen presentation for the activation of virusspecific CD4+ and CD8+ T cell responses.

\section{RESTRICTION FACTORS-BASED THERAPEUTICS}

The implementation of combined antiretroviral therapy (cART) has been a fundamental breakthrough in the treatment of HIV-1 infected individuals. cART maintains viral loads to undetectable levels, limits the occurrence of viral resistance, and drastically reduces the morbidity and mortality rate in HIV1 infected individuals. However, cART does not eliminate the virus from the organism and patients need to adhere to lifelong therapy, which entails drug-related side effects. In addition, treatment interruption results in a rapid viral rebound due to the presence of a latent HIV-1 reservoir $(208,209)$. In light of the studies reviewed here, the development of restriction factorbased therapeutics could provide alternative therapeutic avenues to control HIV-1 by synergizing intrinsic cellular sensing and activation of antiviral immunity.

\section{Type I Interferon Therapies}

Therapeutic approaches to efficiently enhance the expression and restriction activities of A3G, SAMHD1, Tetherin, and TRIM5 $\alpha$ have been proposed to control HIV-1 replication. Restriction factors are generally encoded by IFN-inducible genes, so the use of type I IFN (IFN-I) is being investigated to increase their expression and promote cellular protection from infection. For instance, IFN- $\alpha$ significantly induces
A3G expression in human primary resting $\mathrm{CD} 4+\mathrm{T}$ cells, macrophages, DCs, and endothelial cells in the brain restricting HIV-1 infection (210-212). Overexpression of Tetherin upon IFN- $\alpha$ stimulation overcomes Vpu-mediated antagonism and decreases HIV-1 virion release in vitro (213). Similarly, IFNI treatment has been reported to regulate SAMHD1 function $(214,215)$ in a cell-type specific manner (216). The viral restriction imposed by SAMHD1 and induced by IFN signaling is exerted primarily through its activation via dephosphorylation. Thus, SAMHD1 dephosphorylation is per se a pharmacological target of IFN-I treatment. IFN- $\alpha$ also increases $\operatorname{rhTRIM} 5 \alpha$ expression in rhesus monkey cells and hTRIM5 $\alpha$ in human cells, enhancing their ability to restrict HIV-1 and N-MLV, respectively, (217).

A randomized controlled clinical trial evaluated the effect of IFN- $\alpha$ on HIV-1 viremia in early infected individuals, showing a significant decrease in HIV-1 load in IFN- $\alpha$ treated patients (218). However, only few studies have analyzed the effects of IFN- $\alpha$ treatment on the expression of restriction factors in vivo and the relevance of these factors to control HIV-1 infection. In rhesus macaques, intramuscular IFN- $\alpha 2$ administration upregulated the expression of IFN-stimulated genes, including restriction factors, and delayed systemic SIV infection. Nevertheless, prolonged IFN- $\alpha 2$ treatment caused IFN desensitization and decreased antiviral gene expression, enabling infection to progress thus highlighting the importance of the timing of IFN-induced innate responses (219). In ARTnaïve $\mathrm{HIV}-1 / \mathrm{HCV}$ co-infected patients, IFN- $\alpha$ /ribavirin therapy suppressed HIV-1 viremia which correlated with overexpression of IFN-induced A3G, A3F, and Tetherin in patient-derived CD4+ T cells $(220,221)$, indicating that IFN-induced expression of restriction factors has a direct impact in inhibiting viral replication. Currently, the use of IFN $\alpha-2$ is being tested in clinical trials for HIV-1 infected individuals (ID: NCT03588715; ID: NCT02227277). Besides, other IFN- $\alpha$ subtypes, such as IFN $\alpha-14$, have shown potent antiviral efficacy by inducing the expression of some restriction factors in a humanized mice model (222). Although the stimulation of restriction factors by type I IFNs might be tempting as an experimental approach to block HIV-1, prolonged exposure to type I IFNs has been associated with persistent immune activation and disease progression (223).

\section{Specific Targeting by Small Molecules}

Strategies to develop inhibitors or antagonists targeting HIV1 proteins involved in counteracting restriction factors are currently being investigated with the common goal of enhancing their suppressive activity against HIV-1. For example, structural interactions between Vif-A3G and Vpu-Tetherin were used as a guide for the design of small molecules to block HIV1 replication (224-227). Screening of compounds that inhibit Vif-A3G interaction led to the discovery of several small molecules that protected A3G from Vif-dependent degradation $(228,229)$ or disrupted the assembly of the Vif-ubiquitin ligase complex (230-232). A small molecule interfering with VpuTetherin association that enhances Tetherin expression and potentiates its restriction capacity has also been described (225). 
Although a matter of debate (233), Vpu has been reported to form ion channels that might be involved in blocking Tetherin-mediated viral restriction $(234,235)$. Therefore, the ion channel structure formed by $\mathrm{Vpu}$ could be bait for the development of new antiviral agents to successfully inhibit $\mathrm{Vpu}$ activity increasing Tetherin's antiviral function (236).

Small molecules mimicking $\mathrm{Vpx}$ action and blocking SAMHD1 to induce innate immune signaling and increasing the presentation of viral antigens by DCs are also under investigation (78, 80, 237-239). Interestingly, multiple tyrosine kinase inhibitors (240) and cyclin-dependent kinase (CDK) inhibitors (241-243) impede SAMHD1 phosphorylation, promoting its antiviral activities. In particular, the CDK4/6 inhibitor Palbociclib potently restricts $\mathrm{HIV}-1$ reverse transcription by maintaining SAMHD1 constantly activated (243). In addition, inhibitors of the Protein Kinase $\mathrm{C}$ theta have been proposed as adjuvants of antiretroviral therapy because of their effect on SAMHD1 activation and the consequent reduction of HIV-1 replication (244). Also note that topoisomerase inhibitors and chemotherapeutic drugs, albeit indirectly, trigger SAMHD1 antiviral functions by inducing DNA damage, therefore suppressing HIV-1 infection and limiting the size of the viral reservoir (245). Moreover, small compounds mimicking TRIM $5 \alpha$ capsid interactions could be designed to block retroviral infection in the early steps of the HIV-1 replication cycle (246). In these lines, small molecules and peptides as HIV-1 capsid inhibitors are currently being explored as a new family of antiretroviral drugs (247).

A better identification and mapping of protein-protein surfaces of interactions between restriction factors and their respective antagonizing $\mathrm{HIV}-1$ proteins could guide the design of small molecules for novel therapeutic interventions.

\section{Gene Editing: the Potential of Genetically Engineered TRIM5 $\alpha$ Proteins}

Although potential therapeutic strategies for HIV-1 infected individuals involving A3G, SAMHD1, or Tetherin have been studied (248), all of them tackle HIV-1 replication in later entry, post-reverse transcription, or post-integration events. Also, the antiviral potency of $\mathrm{A} 3 \mathrm{G}$ and Tetherin is limited by Vif and Vpu proteins, respectively, (9, 10, 31, 37, 86, 88, 249, 250). In contrast, TRIM5 $\alpha$ restricts replication immediately after entry and prior to integration. Of note, to date no HIV-1 accessory proteins are capable of antagonizing hTRIM5 $\alpha$ activity (251). These unique features of TRIM $5 \alpha$ activity make genetically engineered TRIM $5 \alpha$-based proteins promising candidates for the development of antiretroviral approaches and gene therapy applications compared to other restriction factors.

In recent years, several studies have supported the feasibility of exploiting TRIM5 $\alpha$ as a target for HIV-1 gene therapy (251). For instance, a single modification of the 332 residue to proline in the PRYSPRY domain of the hTRIM5 $\alpha$, which increases the affinity for the HIV-1 capsid, results in a hTRIM5 $\alpha$ variant able to strongly restrict HIV-1 infection in human cells $(117,252)$. Similarly, an hTRIM5 $\alpha$ mutant generated by PCR-based random mutagenesis and functional screening also showed strong HIV1 restriction capacity (253). Interestingly, R332G-R335G double mutations in hTRIM5 $\alpha$ confer a degree of resistance to HIV-1 infection resembling that of rhTRIM5 $\alpha$. Follow-up investigations demonstrated the ability of R332G-R335G hTRIM5 $\alpha$ mutant to potently inhibit highly diverse HIV-1 strains and clinical isolates bearing CTL escape capsid mutations in human lymphocytes (254). Although additional experiments in primary cells and including other HIV-1 variants would be required, these studies demonstrate the potential of hTRIM $5 \alpha$ mutants as candidates for HIV-1 gene therapy. In these lines, Richardson et al. determined that hTRIM $5 \alpha_{\mathrm{R} 323-\mathrm{R} 332}$ harboring five rhesus substitutions in the PRYSPRY domain confer protein stability and protection from HIV-1 in primary human CD4+ T cells in vivo (255). Chimeric proteins could also be used for instance by replacing 11 amino acids of the PRYSPRY domain of the rhesus macaque ortholog into hTRIM5 $\alpha$, which efficiently restricted HIV-1 infection of CCR5- and CXCR4-tropic HIV-1 clones in CD34+ cell-derived macrophages in vitro, and in mouse-derived thymocytes in vivo (256).

Previous studies have reported that the TRIMCyp fusion protein resulting from swapping the TRIM5 $\alpha$ PRYSPRY domain by CypA retains the same function than TRIM5 $\alpha$, binding to the incoming retroviral capsid and impairing reverse transcription strongly restricting lentiviral infection $(119,126,257)$. Neagu et al. showed that hTRIMCyp successfully inhibits CCR5- and CXCR4-tropic HIV-1 clones as well as primary isolates in CD4+ $\mathrm{T}$ cells and macrophages in vitro. Remarkably, they also found that an experimental humanized mouse model engrafted with human CD4 $+\mathrm{T}$ cells previously transduced with hTRIM5Cyp lentiviral vectors potently restricted HIV-1 (258). Similar to the TRIMCyp fusion construct, fusions between TRIM21 and CypA (TRIM21Cyp) elicited strong anti-HIV effects and maintained the antiviral properties of both TRIM $5 \alpha$ and TRIM21 in human cell lines and primary human T cells (259).

One potential constrain to these therapies is the development of viral escape from TRIM $5 \alpha$ restriction. As for cART, combining TRIM5 $\alpha$ modified proteins with other anti-HIV strategies targeting various steps of HIV-1 replication might prevent HIV1 evasion. For instance, Anderson et al. analyzed the efficacy of a combination anti-HIV lentiviral vector encoding a CCR5 shRNA (pre-entry), a human/rhesus macaque chimeric TRIM5 $\alpha$ (pre-integration), and a transactivation response element (TAR) decoy (post-integration) to block productive HIV-1 infection and to inhibit the formation of novel provirus. This combination anti-HIV lentiviral vector was able to potently restrict HIV1 infection as well as to prevent viral escape mutations (260). Later, Walker et al. evaluated the safety and efficacy of this antiHIV lentiviral vector in CD34+ HSCs in vivo in a humanized murine model. Notably, they reported that mice containing transduced CD34+ HSC with the anti-HIV lentiviral vector presented selective survival advantage when challenged with both R5-tropic BaL or X4-tropic NL4-3 HIV-1 strains (261). This combination anti-HIV-1 lentiviral vector is currently in a phase I/II clinical trial (ID: NCT02797470). The exploitation of the novel CRISPR-Cas9 technology could also be a suitable tool to precisely manipulate $h T R I M 5 \alpha$ gene to increase the affinity 
of hTRIM5 $\alpha$ for the incoming retroviral capsid and enhance antiviral potency $(262,263)$.

\section{CONCLUDING REMARKS AND FUTURE PERSPECTIVES}

Cellular host restriction factors including APOBEC3G, Tetherin, SAMHD1, and TRIM $5 \alpha$ constitute a first barrier of the intrinsic cellular response against HIV-1 and other viral infections. Recent studies highlight the role of these restriction factors as versatile actors at the interplay between innate and adaptive antiviral immunity. Restriction factors can modulate NK cells, DCs, and antiviral $\mathrm{CD} 4+$ and $\mathrm{CD} 8+\mathrm{T}$ cell responses, although the mechanistic details are still not fully understood. The interactions between APOBEC3G, Tetherin, SAMHD1, and TRIM $5 \alpha$ with the intracellular protein degradation pathways, including the UPS, the autophagy and endocytic pathways, may serve as a bridge to promote antiviral cellular immunity. Besides, some of the recently described restriction factors, in particular MARCH2 and IFITMs, may follow similar pathways of intracellular proteins degradation increasing the opportunities to immune regulate antiviral responses. A deeper understanding of the mechanisms underlying the immunomodulatory role of restriction factors is essential if we aim to induce early restriction and potent immune responses to control viral infections. In this way, restriction factors might offer the opportunity to design innovative therapeutic approaches to counteract retroviral replication while promoting effective antiviral cellular immunity.

\section{REFERENCES}

1. Blanco-Melo D, Venkatesh S, Bieniasz PD. Intrinsic cellular defenses against human immunodeficiency viruses. Immunity (2012) 37:399-411. doi: 10.1016/j.immuni.2012.08.013

2. Stremlau M, Owens CM, Perron MJ, Kiessling M, Autissier P, Sodroski J. The cytoplasmic body component TRIM5alpha restricts HIV-1 infection in Old World monkeys. Nature (2004) 427:848-53. doi: 10.1038/nature02343

3. Stremlau M, Perron M, Lee M, Li Y, Song B, Javanbakht $H$, et al. Specific recognition and accelerated uncoating of retroviral capsids by the TRIM5alpha restriction factor. Proc Natl Acad Sci USA. (2006) 103:5514-9. doi: 10.1073/pnas.0509996103

4. Laguette N, Sobhian B, Casartelli N, Ringeard M, Chable-Bessia C, Ségéral E, et al. SAMHD1 is the dendritic- and myeloid-cell-specific HIV-1 restriction factor counteracted by Vpx. Nature (2011) 474:654-7. doi: $10.1038 /$ nature 10117

5. Lahouassa H, Daddacha W, Hofmann H, Ayinde D, Logue EC, Dragin L, et al. SAMHD1 restricts the replication of human immunodeficiency virus type 1 by depleting the intracellular pool of deoxynucleoside triphosphates. Nat Immunol. (2012) 13:223-8. doi: 10.1038/ni.2236

6. Hrecka K, Hao C, Gierszewska M, Swanson SK, Kesik-Brodacka M, Srivastava S, et al. Vpx relieves inhibition of HIV-1 infection of macrophages mediated by the SAMHD1 protein. Nature (2011) 474:658-61. doi: 10.1038/nature10195

7. Zhang H, Yang B, Pomerantz RJ, Zhang C, Arunachalam SC, Gao L. The cytidine deaminase CEM15 induces hypermutation in newly synthesized HIV-1 DNA. Nature (2003) 424:94-8. doi: 10.1038/nature01707

8. Mangeat B, Turelli P, Caron G, Friedli M, Perrin L, Trono D. Broad antiretroviral defence by human APOBEC3G through lethal editing of nascent reverse transcripts. Nature (2003) 424:99-103. doi: $10.1038 /$ nature 01709

\section{AUTHOR CONTRIBUTIONS}

All authors listed have made a substantial, direct and intellectual contribution to the work, and approved it for publication.

\section{FUNDING}

This work was supported by the National Health Institute Carlos III (ISCIII; grants PI14/01058, PI17/00168) and the Gilead Fellowship Program GLD15/00298. JP research team is supported by Redes Temáticas de Investigación en SIDA (ISCIII RETIC RD16/0025/0041); Acción Estratégica en Salud. Plan Nacional de Investigación Científica, Desarrollo e Innovación Tecnológica 2008-2011; Instituto de Salud Carlos III, Fondos FEDER; La Caixa Foundation. JP holds a Miguel Servet II contract (CPII15/00014) funded by ISCIII. AM's work is funded by AR (AutoVirim), ANRS and Sidaction. AM also thanks Sorbonne University, INSERM, and CNRS for continuous support.

\section{ACKNOWLEDGMENTS}

We thank Dr. Serra-Moreno from Texas Tech University and all members of Dr. Prado's research group for their valuable input and constructive feedback to this review. We would like to apologize to the authors whose valuable work could not be discussed due to the focus of the review and length constrains.
9. Neil SJD, Zang T, Bieniasz PD. Tetherin inhibits retrovirus release and is antagonized by HIV-1 Vpu. Nature (2008) 451:425-30. doi: $10.1038 /$ nature 06553

10. Van Damme N, Goff D, Katsura C, Jorgenson RL, Mitchell R, Johnson MC, et al. The interferon-induced protein BST-2 restricts HIV-1 release and is downregulated from the cell surface by the viral Vpu protein. Cell Host Microbe (2008) 3:245-52. doi: 10.1016/j.chom.2008.03.001

11. Goujon C, Moncorgé O, Bauby H, Doyle T, Ward CC, Schaller T, et al. Human MX2 is an interferon-induced post-entry inhibitor of HIV-1 infection. Nature (2013) 502:559-62. doi: 10.1038/nature12542

12. Usami Y, Wu Y, Göttlinger HG. SERINC3 and SERINC5 restrict HIV1 infectivity and are counteracted by Nef. Nature (2015) 526:218-23. doi: 10.1038/nature15400

13. Lu J, Pan Q, Rong L, Liu S-L, Liang C, Liang C. The IFITM proteins inhibit HIV-1 infection. J Virol. (2011) 85:2126-37. doi: 10.1128/JVI.01531-10

14. Li M, Kao E, Gao X, Sandig H, Limmer K, Pavon-Eternod M, et al. Codonusage-based inhibition of HIV protein synthesis by human schlafen 11 . Nature (2012) 491:125-8. doi: 10.1038/nature11433

15. Tada T, Zhang Y, Koyama T, Tobiume M, Tsunetsugu-Yokota Y, Yamaoka S, et al. MARCH8 inhibits HIV-1 infection by reducing virion incorporation of envelope glycoproteins. Nat Med. (2015) 21:1502-7. doi: 10.1038/nm.3956

16. Zhang $\mathrm{Y}$, Lu J, Liu X. MARCH2 is upregulated in HIV-1 infection and inhibits HIV-1 production through envelope protein translocation or degradation. Virology (2018) 518:293-300. doi: 10.1016/j.virol.2018. 02.003

17. Gasteiger G, Rudensky AY. Opinion: interactions of innate and adaptive lymphocytes. Nat Rev Immunol. (2014) 14:631-9. doi: 10.1038/nri3726

18. Rivière Y, McChesney MB, Porrot F, Tanneau-Salvadori F, Sansonetti P, Lopez $\mathrm{O}$, et al. Gag-specific cytotoxic responses to HIV type 1 are associated with a decreased risk of progression to AIDS-related complex or AIDS. AIDS Res Hum Retroviruses (1995) 11:903-7. 
19. Ogg GS, Kostense S, Klein MR, Jurriaans S, Hamann D, McMichael AJ, et al. Longitudinal phenotypic analysis of human immunodeficiency virus type 1-specific cytotoxic T lymphocytes: correlation with disease progression. $J$ Virol. (1999) 73:9153-60.

20. Borrow P, Lewicki H, Hahn BH, Shaw GM, Oldstone MB. Virus-specific CD8+ cytotoxic T-lymphocyte activity associated with control of viremia in primary human immunodeficiency virus type 1 infection. J Virol. (1994) 68:6103-10.

21. Rosenberg ES, Altfeld M, Poon SH, Phillips MN, Wilkes BM, Eldridge RL, et al. Immune control of HIV-1 after early treatment of acute infection. Nature (2000) 407:523-6. doi: 10.1038/35035103

22. McMichael AJ, Borrow P, Tomaras GD, Goonetilleke N, Haynes BF. The immune response during acute HIV-1 infection: clues for vaccine development. Nat Rev Immunol. (2010) 10:11-23. doi: 10.1038/nri2674

23. Goonetilleke N, Liu MKP, Salazar-Gonzalez JF, Ferrari G, Giorgi E, Ganusov $\mathrm{VV}$, et al. The first $\mathrm{T}$ cell response to transmitted/founder virus contributes to the control of acute viremia in HIV-1 infection. J Exp Med. (2009) 206:1253-72. doi: 10.1084/jem.20090365

24. Kiepiela P, Ngumbela K, Thobakgale C, Ramduth D, Honeyborne I, Moodley $\mathrm{E}$, et al. CD8+ T-cell responses to different HIV proteins have discordant associations with viral load. Nat Med. (2007) 13:46-53. doi: 10.1038/nm1520

25. Sáez-Cirión A, Lacabaratz C, Lambotte O, Versmisse P, Urrutia A, Boufassa F, et al. HIV controllers exhibit potent CD8 T cell capacity to suppress HIV infection ex vivo and peculiar cytotoxic T lymphocyte activation phenotype. Proc Natl Acad Sci USA. (2007) 104:6776-81. doi: 10.1073/pnas.0611244104

26. Pereyra F, Jia X, Mclaren PJ, Kadie CM, Carlson JM, Heckerman D, et al. The major genetic determinants of HIV-1 control affect HLA class I peptide presentation. Science (2011) 330:1551-7. doi: 10.1126/science.1195271

27. Suspene R, Guetard D, Henry M, Sommer P, Wain-Hobson S, Vartanian JP. Extensive editing of both hepatitis B virus DNA strands by APOBEC3 cytidine deaminases in vitro and in vivo. Proc Natl Acad Sci USA. (2005) 102:8321-6. doi: 10.1073/pnas.0408223102

28. Mahieux R, Suspène R, Delebecque F, Henry M, Schwartz O, Wain-Hobson $\mathrm{S}$, et al. Extensive editing of a small fraction of human T-cell leukemia virus type 1 genomes by four APOBEC3 cytidine deaminases. J Gen Virol. (2005) 86:2489-94. doi: 10.1099/vir.0.80973-0

29. Delebecque F, Suspene R, Calattini S, Casartelli N, Saib A, Froment A, et al. Restriction of foamy viruses by APOBEC cytidine deaminases. J Virol. (2006) 80:605-14. doi: 10.1128/JVI.80.2.605-614.2006

30. Browne EP, Littman DR. Species-specific restriction of Apobec3-mediated hypermutation. J Virol. (2008) 82:1305-13. doi: 10.1128/JVI.01371-07

31. Sheehy AM, Gaddis NC, Choi JD, Malim MH. Isolation of a human gene that inhibits HIV-1 infection and is suppressed by the viral Vif protein. Nature (2002) 418:646-50. doi: 10.1038/nature00939

32. Harris RS, Bishop KN, Sheehy AM, Craig HM, Petersen-Mahrt SK, Watt IN, et al. DNA deamination mediates innate immunity to retroviral infection. Cell (2003) 113:803-9. doi: 10.1016/S0092-8674(03)00423-9

33. Newman ENC, Holmes RK, Craig HM, Klein KC, Lingappa JR, Malim $\mathrm{MH}$, et al. Antiviral function of APOBEC3G can be dissociated from cytidine deaminase activity. Curr Biol. (2005) 15:166-70. doi: 10.1016/j.cub.2004.12.068

34. Henriet S, Mercenne G, Bernacchi S, Paillart J-C, Marquet R. Tumultuous relationship between the human immunodeficiency virus type 1 Viral Infectivity Factor (Vif) and the human APOBEC-3G and APOBEC3F restriction factors. Microbiol Mol Biol Rev. (2009) 73:211-32. doi: 10.1128/MMBR.00040-08

35. Marin M, Rose KM, Kozak SL, Kabat D. HIV-1 Vif protein binds the editing enzyme APOBEC3G and induces its degradation. Nat Med. (2003) 9:1398-403. doi: 10.1038/nm946

36. Yu X, Yu Y, Liu B, Luo K, Kong W, Mao P, et al. Induction of APOBEC3G ubiquitination and degradation by an HIV-1 Vif-Cul5-SCF complex. Science (2003) 302:1056-60. doi: 10.1126/science.1089591

37. Sheehy AM, Gaddis NC, Malim MH. The antiretroviral enzyme APOBEC3G is degraded by the proteasome in response to HIV-1 Vif. Nat Med. (2003) 9:1404-7. doi: 10.1038/nm945

38. Mehle A, Strack B, Ancuta P, Zhang C, McPike M, Gabuzda D. Vif overcomes the innate antiviral activity of APOBEC $3 \mathrm{G}$ by promoting its degradation in the ubiquitin-proteasome pathway. J Biol Chem. (2004) 279:7792-8. doi: 10.1074/jbc.M313093200

39. Conticello SG. The AID/APOBEC family of nucleic acid mutators. Genome Biol. (2008) 9:229. doi: 10.1186/gb-2008-9-6-229

40. Moris A, Murray S, Cardinaud S. AID and APOBECs span the gap between innate and adaptive immunity. Front Microbiol. (2014) 5:1-13. doi: 10.3389/fmicb.2014.00534

41. Koning FA, Newman ENC, Kim E-Y, Kunstman KJ, Wolinsky SM, Malim MH. Defining APOBEC3 expression patterns in human tissues and hematopoietic cell subsets. J Virol. (2009) 83:9474-85. doi: 10.1128/JVI.01089-09

42. Oliva H, Pacheco R, Martinez-Navio JM, Rodríguez-García M, NaranjoGómez M, Climent N, et al. Increased expression with differential subcellular location of cytidine deaminase APOBEC3G in human CD4(+) T-cell activation and dendritic cell maturation. Immunol Cell Biol. (2016) 94:689700. doi: $10.1038 /$ icb. 2016.28

43. Sarkis PTN, Ying S, Xu R, Yu X-F. STAT1-Independent cell type-specific regulation of antiviral APOBEC3G by IFN- $\alpha$. J Immunol. (2006) 177:453040. doi: 10.4049/jimmunol.177.7.4530

44. Peng G, Greenwell-Wild T, Nares S, Jin W, Lei KJ, Rangel ZG, et al. Myeloid differentiation and susceptibility to HIV-1 are linked to APOBEC3 expression. Blood (2007) 110:393-400. doi: 10.1182/blood-2006-10-051763

45. Stopak KS, Chiu Y-L, Kropp J, Grant RM, Greene WC. Distinct patterns of cytokine regulation of APOBEC3G expression and activity in primary lymphocytes, macrophages, and dendritic cells. J Biol Chem. (2006) 282:3539-46. doi: 10.1074/jbc.M610138200

46. Norman JM, Mashiba M, McNamara LA, Onafuwa-Nuga A, Chiari-Fort E, Shen $\mathrm{W}$, et al. The antiviral factor APOBEC3G enhances the recognition of HIV-infected primary T cells by natural killer cells. Nat Immunol. (2011) 12:975-83. doi: 10.1038/ni.2087

47. Halemano K, Barrett BS, Heilman KJ, Morrison TE, Santiago ML. Requirement for $\mathrm{Fc}$ effector mechanisms in the APOBEC3/Rfv3dependent neutralizing antibody response. J Virol. (2015) 89:4011-4. doi: 10.1128/JVI.03399-14

48. Santiago ML, Benitez RL, Montano M, Hasenkrug KJ, Greene WC. Innate retroviral restriction by Apobec3 promotes antibody affinity maturation in vivo. J Immunol. (2010) 185:1114-23. doi: 10.4049/jimmunol.1001143

49. Smith DS, Guo K, Barrett BS, Heilman KJ, Evans LH, Hasenkrug $\mathrm{KJ}$, et al. Noninfectious retrovirus particles drive the Apobec3/Rfv3 dependent neutralizing antibody response. PLoS Pathog. (2011) 7:e1002284. doi: 10.1371/journal.ppat.1002284

50. Casartelli N, Guivel-Benhassine F, Bouziat R, Brandler S, Schwartz O, Moris A. The antiviral factor APOBEC3G improves CTL recognition of cultured HIV-infected T cells. J Exp Med. (2010) 207:39-49. doi: 10.1084/jem.20091933

51. Schubert U, Antón LC, Gibbs J, Norbury CC, Yewdell JW, Bennink JR. Rapid degradation of a large fraction of newly synthesized proteins by proteasomes. Nature (2000) 404:770-4. doi: 10.1038/35008096

52. Cardinaud S, Urrutia A, Rouers A, Coulon PG, Kervevan J, Richetta C, et al. Triggering of TLR-3,-4, NOD2, and DC-SIGN reduces viral replication and increases T-cell activation capacity of HIV-infected human dendritic cells. Eur J Immunol. (2017) 47:818-29. doi: 10.1002/eji.201646603

53. Monajemi M, Woodworth CF, Zipperlen K, Gallant M, Grant MD, Larijani M. Positioning of APOBEC3G/F mutational hotspots in the human immunodeficiency virus genome favors reduced recognition by $\mathrm{CD} 8+\mathrm{T}$ cells. PLoS ONE (2014) 9:e93428. doi: 10.1371/journal.pone.0093428

54. Grant M, Larijani M. Evasion of adaptive immunity by HIV through the action of host APOBEC3G/F enzymes. AIDS Res Ther. (2017) 14:10-13. doi: 10.1186/s12981-017-0173-8

55. Squires KD, Monajemi M, Woodworth CF, Grant MD, Larijani M. Impact of APOBEC mutations on CD8 $+\mathrm{T}$ cell recognition of hiv epitopes varies depending on the restricting HLA. J Acquir Immune Defic Syndr. (2015) 70:172-8. doi: 10.1097/QAI.0000000000000689

56. Pollack RA, Jones RB, Pertea M, Bruner KM, Martin AR, Thomas AS, et al. Defective HIV-1 proviruses are expressed and can be recognized by cytotoxic T lymphocytes, which shape the proviral landscape. Cell Host Microbe (2017) 21:494-506.e4. doi: 10.1016/j.chom.2017.03.008 
57. Wang Y, Bergmeier LA, Stebbings R, Seidl T, Whittall T, Singh M, et al. Mucosal immunization in macaques upregulates the innate APOBEC 3G anti-viral factor in CD4(+) memory T cells. Vaccine (2009) 27:870-81. doi: 10.1016/j.vaccine.2008.11.084

58. Sui Y, Zhu Q, Gagnon S, Dzutsev A, Terabe M, Vaccari M, et al. Innate and adaptive immune correlates of vaccine and adjuvant-induced control of mucosal transmission of SIV in macaques. Proc Natl Acad Sci USA. (2010) 107:9843-8. doi: 10.1073/pnas.0911932107

59. Wang Y, Whittall T, Rahman D, Bunnik EM, Vaughan R, Schøller J, et al. The role of innate APOBEC3G and adaptive AID immune responses in HLAHIV/SIV immunized SHIV infected macaques. PLoS ONE (2012) 7:e34433. doi: 10.1371/journal.pone.0034433

60. Seidl T, Whittall T, Babaahmady K, Lehner T. B-cell agonists upregulate AID and APOBEC3G deaminases, which induce IgA and IgG class antibodies and anti-viral function. Immunology (2012) 135:207-15. doi: 10.1111/j.1365-2567.2011.03524.x

61. Goldstone DC, Ennis-Adeniran V, Hedden JJ, Groom HCT, Rice GI, Christodoulou E, et al. HIV-1 restriction factor SAMHD1 is a deoxynucleoside triphosphate triphosphohydrolase. Nature (2011) 480:379-82. doi: 10.1038/nature10623

62. Powell RD, Holland PJ, Hollis T, Perrino FW. Aicardi-Goutières syndrome gene and HIV-1 restriction factor SAMHD1 is a dGTP-regulated deoxynucleotide triphosphohydrolase. J Biol Chem. (2011) 286:43596-600. doi: 10.1074/jbc.C111.317628

63. Ryoo J, Choi J, Oh C, Kim S, Seo M, Kim S-Y, et al. The ribonuclease activity of SAMHD1 is required for HIV-1 restriction. Nat Med. (2014) 20:936-41. doi: $10.1038 / \mathrm{nm} .3626$

64. Choi J, Ryoo J, Oh C, Hwang S, Ahn K. SAMHD1 specifically restricts retroviruses through its RNase activity. Retrovirology (2015) 12:1-12. doi: 10.1186/s12977-015-0174-4

65. Antonucci JM, St. Gelais C, de Silva S, Yount JS, Tang C, Ji X, et al. SAMHD1mediated HIV-1 restriction in cells does not involve ribonuclease activity. Nat Med. (2016) 22:1072-4. doi: 10.1038/nm.4163

66. Ballana E, Esté JA. SAMHD1: at the crossroads of cell proliferation, immune responses, and virus restriction. Trends Microbiol. (2015) 23:68092. doi: 10.1016/j.tim.2015.08.002

67. Goujon C, Arfi V, Pertel T, Luban J, Lienard J, Rigal D, et al. Characterization of simian immunodeficiency virus SIVSM/human immunodeficiency virus type 2 Vpx function in human myeloid cells. J Virol. (2008) 82:12335-45. doi: 10.1128/JVI.01181-08

68. Ahn J, Hao C, Yan J, DeLucia M, Mehrens J, Wang C, et al. $\mathrm{HIV} /$ simian immunodeficiency virus (SIV) accessory virulence factor Vpx loads the host cell restriction factor SAMHD1 onto the E3 ubiquitin ligase complex CRL4DCAF1. J Biol Chem. (2012) 287:12550-8. doi: 10.1074/jbc.M112.340711

69. Descours B, Cribier A, Chable-Bessia C, Ayinde D, Rice G, Crow Y, et al. SAMHD1 restricts HIV-1 reverse transcription in quiescent CD4(+) T-cells. Retrovirology (2012) 9:87. doi: 10.1186/1742-4690-9-87

70. Cribier A, Descours B, Valadão ALC, Laguette $\mathrm{N}$, Benkirane $\mathrm{M}$. Phosphorylation of SAMHD1 by cyclin A2/CDK1 regulates its restriction activity toward HIV-1. Cell Rep. (2013) 3:1036-1043. doi: 10.1016/j.celrep.2013.03.017

71. White TEE, Brandariz-Nuñez A, Valle-Casuso JCC, Amie S, Nguyen LAA, Kim B, et al. The retroviral restriction ability of SAMHD1, but not its deoxynucleotide triphosphohydrolase activity, is regulated by phosphorylation. Cell Host Microbe (2014) 13:441-51. doi: 10.1016/j.chom.2013.03.005

72. Pauls E, Ruiz A, Badia R, Permanyer M, Gubern A, Riveira-Muñoz E, et al. Cell cycle control and HIV-1 susceptibility are linked by CDK6dependent CDK2 phosphorylation of SAMHD1 in myeloid and lymphoid cells. J Immunol. (2014) 193:1988-97. doi: 10.4049/jimmunol.1400873

73. Ruiz A, Pauls E, Badia R, Torres-Torronteras J, Riveira-Muñoz E, Clotet B, et al. Cyclin D3-dependent control of the dNTP pool and HIV1 replication in human macrophages. Cell Cycle (2015) 14:1657-65. doi: 10.1080/15384101.2015.1030558

74. Crow YJ, Manel N. Aicardi-Goutières syndrome and the type I interferonopathies. Nat Rev Immunol. (2015) 15:429-40. doi: $10.1038 /$ nri3850
75. Rice GI, Bond J, Asipu A, Brunette RL, Manfield IW, Carr IM, et al. Mutations involved in Aicardi-Goutières syndrome implicate SAMHD1 as regulator of the innate immune response. Nat Genet. (2009) 41:829-32. doi: 10.1038/ng.373

76. Chen S, Bonifati S, Qin Z, St. Gelais C, Kodigepalli KM, Barrett BS, et al. SAMHD1 suppresses innate immune responses to viral infections and inflammatory stimuli by inhibiting the NF- $\kappa \mathrm{B}$ and interferon pathways. Proc Natl Acad Sci USA. (2018) 115:E3798-807. doi: 10.1073/pnas.18012 13115

77. Manel N, Hogstad B, Wang Y, Levy DE, Unutmaz D, Littman DR. A cryptic sensor for HIV-1 activates antiviral innate immunity in dendritic cells. Nature (2010) 467:214-7. doi: 10.1038/nature09337

78. Maelfait J, Bridgeman A, Benlahrech A, Cursi C, Rehwinkel J. Restriction by SAMHD1 limits cGAS/STING-dependent innate and adaptive immune responses to HIV-1. Cell Rep. (2016) 16:1492-501. doi: 10.1016/j.celrep.2016.07.002

79. Hertoghs N, van der Aar AMG, Setiawan LC, Kootstra NA, Gringhuis SI, Geijtenbeek TBH. SAMHD1 degradation enhances active suppression of dendritic cell maturation by HIV-1. J Immunol. (2015) 194:4431-7. doi: 10.4049/jimmunol.1403016

80. Ayinde D, Bruel T, Cardinaud S, Porrot F, Prado JG, Moris A, et al. SAMHD1 limits HIV-1 antigen presentation by monocyte-derived dendritic cells. J Virol. (2015) 89:6994-7006. doi: 10.1128/JVI.00069-15

81. Martin-Gayo E, Buzon MJ, Ouyang Z, Hickman T, Cronin J, Pimenova D, et al. Potent cell-intrinsic immune responses in dendritic cells facilitate HIV1-specific T cell immunity in HIV-1 elite controllers. PLoS Pathog. (2015) 11:e1004930. doi: 10.1371/journal.ppat.1004930

82. Riveira-Muñoz E, Ruiz A, Pauls E, Permanyer M, Badia R, Mothe B, et al. Increased expression of SAMHD1 in a subset of HIV-1 elite controllers. $J$ Antimicrob Chemother. (2014) 69:3057-60. doi: 10.1093/jac/dku276

83. Buchanan EL, McAlexander MA, Witwer KW. SAMHD1 expression in blood cells of HIV-1 elite suppressors and viraemic progressors. J Antimicrob Chemother. (2015) 70:954-6. doi: 10.1093/jac/dku428

84. Perez-Caballero D, Zang T, Ebrahimi A, McNatt MW, Gregory DA, Johnson MC, et al. Tetherin inhibits HIV-1 release by directly tethering virions to cells. Cell (2009) 139:499-511. doi: 10.1016/j.cell.2009.08.039

85. Miyakawa K, Ryo A, Murakami T, Ohba K, Yamaoka S, Fukuda M, et al. BCA2/Rabring7 promotes tetherin-dependent HIV-1 restriction. PLoS Pathog. (2009) 5:e1000700. doi: 10.1371/journal.ppat.1000700

86. Iwabu Y, Fujita H, Kinomoto M, Kaneko K, Ishizaka Y, Tanaka Y, et al. HIV1 accessory protein $\mathrm{Vpu}$ internalizes cell-surface BST-2/tetherin through transmembrane interactions leading to lysosomes. J Biol Chem. (2009) 284:35060-72. doi: 10.1074/jbc.M109.058305

87. Douglas JL, Viswanathan K, McCarroll MN, Gustin JK, Fruh K, Moses AV, et al. Vpu directs the degradation of the human immunodeficiency virus restriction factor BST-2/tetherin via a TrCP-dependent mechanism. J Virol. (2009) 83:7931-47. doi: 10.1128/JVI.00242-09

88. Mangeat B, Gers-Huber G, Lehmann M, Zufferey M, Luban J, Piguet V. HIV-1 Vpu neutralizes the antiviral factor tetherin/BST-2 by binding it and directing its beta-TrCP2-dependent degradation. PLoS Pathog. (2009) 5:e1000574. doi: 10.1371/journal.ppat.1000574

89. Mitchell RS, Katsura C, Skasko MA, Fitzpatrick K, Lau D, Ruiz A, et al. Vpu antagonizes BST-2-mediated restriction of HIV-1 release via betaTrCP and endo-lysosomal trafficking. PLoS Pathog. (2009) 5:e1000450. doi: 10.1371/journal.ppat.1000450

90. Tervo H-M, Homann S, Ambiel I, Fritz JV, Fackler OT, Keppler OT. $\beta$-TrCP is dispensable for Vpu's ability to overcome the CD317/Tetherinimposed restriction to HIV-1 release. Retrovirology (2011) 8:9. doi: 10.1186/1742-4690-8-9

91. Dubé M, Bhusan Roy B, Guiot-Guillain P, Binette J, Mercier J, Chiasson A, et al. Antagonism of tetherin restriction of HIV-1 release by $\mathrm{Vpu}$ involves binding and sequestration of the restriction factor in a perinuclear compartment. PLoS Pathog. (2010) 6:e1000856. doi: 10.1371/journal.ppat.1000856

92. Madjo U, Leymarie O, Frémont S, Kuster A, Nehlich M, Gallois-Montbrun $\mathrm{S}$, et al. LC3C contributes to Vpu-mediated antagonism of BST2/tetherin restriction on HIV-1 release through a non-canonical autophagy pathway. Cell Rep. (2016) 17:2221-33. doi: 10.1016/j.celrep.2016.10.045 
93. Le Tortorec A, Neil SJD. Antagonism to and intracellular sequestration of human tetherin by the human immunodeficiency virus type 2 envelope glycoprotein. J Virol. (2009) 83:11966-78. doi: 10.1128/JVI.01515-09

94. Jia B, Serra-Moreno R, Neidermyer W, Rahmberg A, Mackey J, Fofana I Ben, et al. Species-specific activity of SIV Nef and HIV-1 Vpu in overcoming restriction by tetherin/BST2. PLoS Pathog. (2009) 5:e1000429. doi: 10.1371/journal.ppat.1000429

95. Sauter D, Schindler M, Specht A, Landford WN, Münch J, Kim K-A, et al. Tetherin-driven adaptation of Vpu and Nef function and the evolution of pandemic and nonpandemic HIV-1 strains. Cell Host Microbe (2009) 6:409-21. doi: 10.1016/j.chom.2009.10.004

96. Zhang F, Wilson SJ, Landford WC, Virgen B, Gregory D, Johnson MC, et al. Nef proteins from simian immunodeficiency viruses are tetherin antagonists. Cell Host Microbe (2009) 6:54-67. doi: 10.1016/j.chom.2009.05.008

97. Cocka LJ, Bates P. Identification of alternatively translated Tetherin isoforms with differing antiviral and signaling activities. PLoS Pathog. (2012) 8:e1002931. doi: 10.1371/journal.ppat.1002931

98. Weinelt J, Neil SJD. Differential sensitivities of tetherin isoforms to counteraction by primate lentiviruses. J Virol. (2014) 88:5845-58. doi: 10.1128/JVI.03818-13

99. Galão RP, Le Tortorec A, Pickering S, Kueck T, Neil SJD. Innate sensing of HIV-1 assembly by Tetherin induces NFKB-dependent proinflammatory responses. Cell Host Microbe (2012) 12:633-44. doi: 10.1016/j.chom.2012.10.007

100. Tokarev A, Suarez M, Kwan W, Fitzpatrick K, Singh R, Guatelli J. Stimulation of NF-кB activity by the HIV restriction factor BST2. J Virol. (2013) 87:2046-57. doi: 10.1128/JVI.02272-12

101. Galão RP, Pickering S, Curnock R, Neil SJD. Retroviral retention activates a Syk-dependent HemITAM in human tetherin. Cell Host Microbe (2014) 16:291-303. doi: 10.1016/j.chom.2014.08.005

102. Sauter D, Hotter D, Van Driessche B, Stürzel CM, Kluge SF, Wildum S, et al. Differential regulation of NF- $\kappa \mathrm{B}$-mediated proviral and antiviral host gene expression by primate lentiviral nef and vpu proteins. Cell Rep. (2015) 10:586-99. doi: 10.1016/j.celrep.2014.12.047

103. Bego MG, Côté É, Aschman N, Mercier J, Weissenhorn W, Cohen ÉA. Vpu exploits the cross-talk between BST2 and the ILT7 receptor to suppress anti-HIV-1 responses by plasmacytoid dendritic cells. PLoS Pathog. (2015) 11:e1005024. doi: 10.1371/journal.ppat.1005024

104. Cao W, Bover L, Cho M, Wen X, Hanabuchi S, Bao M, et al. Regulation of TLR7/9 responses in plasmacytoid dendritic cells by BST2 and ILT7 receptor interaction. J Exp Med. (2009) 206:1603-14. doi: 10.1084/jem.200 90547

105. Arias JF, Heyer LN, von Bredow B, Weisgrau KL, Moldt B, Burton DR, et al. Tetherin antagonism by Vpu protects HIV-infected cells from antibodydependent cell-mediated cytotoxicity. Proc Natl Acad Sci USA. (2014) 111:6425-30. doi: 10.1073/pnas.1321507111

106. Richard J, Prévost J, von Bredow B, Ding S, Brassard N, Medjahed H, et al. BST-2 Expression modulates small CD4-mimetic sensitization of HIV1 -infected cells to antibody-dependent cellular cytotoxicity. J Virol. (2017) 91:e00219-17. doi: 10.1128/JVI.00219-17

107. Beignon A-S, McKenna K, Skoberne M, Manches O, DaSilva I, Kavanagh DG, et al. Endocytosis of HIV-1 activates plasmacytoid dendritic cells via Toll-like receptor- viral RNA interactions. J Clin Invest. (2005) 115:3265-75. doi: 10.1172/JCI26032

108. Li SX, Barrett BS, Heilman KJ, Messer RJ, Liberatore RA, Bieniasz PD, et al. Tetherin promotes the innate and adaptive cell-mediated immune response against retrovirus infection in vivo. J Immunol. (2014) 193:306-16. doi: 10.4049/jimmunol.1400490

109. Li SX, Barrett BS, Guo K, Kassiotis G, Hasenkrug KJ, Dittmer U, et al. Tetherin/BST-2 promotes dendritic cell activation and function during acute retrovirus infection. Sci Rep. (2016) 6:1-12. doi: 10.1038/srep20425

110. Han K, Lou DI, Sawyer SL. Identification of a genomic reservoir for new trim genes in primate genomes. PLoS Genet. (2011) 7:e1002388. doi: 10.1371/journal.pgen.1002388

111. Ozato K, Shin D, Chang T, Morse H. TRIM famiy proteins and their emerging roles in innate immunity. Nat Rev Immunol. (2012) 8:849-60. doi: $10.1038 / \mathrm{nri} 2413$
112. Hatakeyama S. TRIM family proteins: roles in autophagy, immunity, and carcinogenesis. Trends Biochem Sci. (2017) 42:297-311. doi: 10.1016/j.tibs.2017.01.002

113. Rajsbaum R, García-Sastre A, Versteeg GA. TRIMmunity: The roles of the TRIM E3-ubiquitin ligase family in innate antiviral immunity. $J$ Mol Biol. (2014) 426:1265-84. doi: 10.1016/j.jmb.2013.12.005

114. Nisole S, Stoye JP, Saïb A. TRIM family proteins: retroviral restriction and antiviral defence. Nat Rev Microbiol. (2005) 3:799-808. doi: $10.1038 /$ nrmicro1248

115. Sawyer SL, Wu LI, Emerman M, Malik HS. Positive selection of primate TRIM5 identifies a critical species-specific retroviral restriction domain. Proc Natl Acad Sci USA. (2005) 102:2832-7. doi: 10.1073/pnas.0409853102

116. Stremlau M, Perron M, Welikala S, Sodroski J. Species-specific variation in the B30.2(SPRY) domain of TRIM5alpha determines the potency of human immunodeficiency virus restriction. J Virol. (2005) 79:3139-45. doi: 10.1128/JVI.79.5.3139-3145.2005

117. Yap MW, Nisole S, Stoye JP. A single amino acid change in the SPRY domain of human Trim5alpha leads to HIV-1 restriction. Curr Biol. (2005) 15:73-8. doi: 10.1016/j.cub.2004.12.042

118. Goff SP. Retrovirus restriction factors. Mol Cell (2004) 16:849-59. doi: 10.1016/j.molcel.2004.12.001

119. Sayah DM, Sokolskaja E, Berthoux L, Luban J. Cyclophilin A retrotransposition into TRIM5 explains owl monkey resistance to HIV-1. Nature (2004) 430:569-73. doi: 10.1038/nature02777

120. Perez-Caballero D, Hatziioannou T, Yang A, Cowan S, Bieniasz PD. Human tripartite motif 5alpha domains responsible for retrovirus restriction activity and specificity. J Virol. (2005) 79:8969-78. doi: 10.1128/JVI.79.14.8969-8978.2005

121. Javanbakht H, Diaz-Griffero F, Stremlau M, Si Z, Sodroski J. The contribution of RING and B-box 2 domains to retroviral restriction mediated by monkey TRIM5 $\alpha$. J Biol Chem. (2005) 280:26933-40. doi: 10.1074/jbc.M502145200

122. Ribeiro CMS, Sarrami-Forooshani R, Setiawan LC, Zijlstra-Willems EM, van Hamme JL, Tigchelaar W, et al. Receptor usage dictates HIV-1 restriction by human TRIM5 $\alpha$ in dendritic cell subsets. Nature (2016) 540:448-52. doi: $10.1038 /$ nature20567

123. Portilho DMDM, Fernandez J, Ringeard M, Machado AK, Boulay A, Mayer $M$, et al. Endogenous TRIM5 $\alpha$ function is regulated by SUMOylation and nuclear sequestration for efficient innate sensing in dendritic cells. Cell Rep. (2016) 14:355-69. doi: 10.1016/j.celrep.2015.12.039

124. Rajsbaum R, Stoye JP, O'Garra A. Type I interferon-dependent and independent expression of tripartite motif proteins in immune cells. Eur J Immunol. (2008) 38:619-30. doi: 10.1002/eji.200737916

125. Yap MW, Nisole S, Lynch C, Stoye JP. Trim5alpha protein restricts both HIV1 and murine leukemia virus. Proc Natl Acad Sci USA. (2004) 101:10786-91. doi: 10.1073/pnas.0402876101

126. Wilson SJ, Webb BLJ, Ylinen LMJ, Verschoor E, Heeney JL, Towers GJ. Independent evolution of an antiviral TRIMCyp in rhesus macaques. Proc Natl Acad Sci USA. (2008) 105:3557-62. doi: 10.1073/pnas.0709003105

127. Newman RM, Hall L, Connole M, Chen G-L, Sato S, Yuste E, et al. Balancing selection and the evolution of functional polymorphism in Old World monkey TRIM5alpha. Proc Natl Acad Sci USA. (2006) 103:19134-9. doi: 10.1073 /pnas.0605838103

128. Hatziioannou T, Perez-Caballero D, Yang A, Cowan S, Bieniasz PD. Retrovirus resistance factors Ref1 and Lv1 are species-specific variants of TRIM5alpha. Proc Natl Acad Sci USA. (2004) 101:10774-9. doi: 10.1073/pnas.0402361101

129. Keckesova Z, Ylinen LMJ, Towers GJ. The human and African green monkey TRIM5 $\alpha$ genes encode Ref1 and Lv1 retroviral restriction factor activities. Proc Natl Acad Sci USA. (2004) 101:10780-5. doi: 10.1073/pnas.0402474101

130. Javanbakht H, An P, Gold B, Petersen DC, O'Huigin C, Nelson GW, et al. Effects of human TRIM $5 \alpha$ polymorphisms on antiretroviral function and susceptibility to human immunodeficiency virus infection. Virology (2006) 354:15-27. doi: 10.1016/j.virol.2006.06.031

131. Sawyer SL, Wu LI, Akey JM, Emerman M, Malik HS. High-frequency persistence of an impaired allele of the retroviral defense gene TRIM5 $\alpha$ in humans. Curr Biol. (2006) 16:95-100. doi: 10.1016/j.cub.2005.11.045 
132. Singh H, Samani D, Ghate MV, Gangakhedkar RR. Impact of cellular restriction gene (TRIM5 $\alpha$, BST-2) polymorphisms on the acquisition of HIV1 and disease progression. J Gene Med. (2017)e3004. doi: 10.1002/jgm.3004

133. Celerino da Silva R, Coelho AVC, Arraes LC, Brandão LAC, Crovella S, Guimarães RL. TRIM5 gene polymorphisms in HIV-1-infected patients and healthy controls from Northeastern Brazil. Immunol Res. (2016) 64:1237-42. doi: 10.1007/s12026-016-8810-1

134. Price H, Lacap P, Tuff J, Wachihi C, Kimani J, Ball TB, et al. A TRIM5alpha exon 2 polymorphism is associated with protection from HIV1 infection in the Pumwani sex worker cohort. AIDS (2010) 24:1813-21. doi: 10.1097/QAD.0b013e32833b5256

135. Speelmon EC, Livingston-Rosanoff D, Li SS, Vu Q, Bui J, Geraghty DE, et al. Genetic association of the antiviral restriction factor TRIM5 $\alpha$ with human immunodeficiency virus type 1 infection. J Virol. (2006) 80:2463-71. doi: 10.1128/JVI.80.5.2463-2471.2006

136. Van Manen D, Rits MAN, Beugeling C, Van Dort K, Schuitemaker $\mathrm{H}$, Kootstra NA. The effect of Trim5 polymorphisms on the clinical course of HIV-1 infection. PLoS Pathog. (2008) 4:e18. doi: 10.1371/journal.ppat.0040018

137. Battivelli E, Migraine J, Lecossier D, Yeni P, Clavel F, Hance AJ. Gag cytotoxic T lymphocyte escape mutations can increase sensitivity of HIV-1 to human TRIM5 $\alpha$, linking intrinsic and acquired immunity. J Virol. (2011) 85:1184654. doi: 10.1128/JVI.05201-11

138. Kutluay SB, Perez-Caballero D, Bieniasz PD. Fates of retroviral core components during unrestricted and TRIM5-restricted infection. PLoS Pathog. (2013) 9:e1003214. doi: 10.1371/journal.ppat.1003214

139. Black LR, Aiken C. TRIM $5 \alpha$ disrupts the structure of assembled HIV-1 capsid complexes in vitro. J Virol. (2010) 84:6564-9. doi: 10.1128/JVI.00210-10

140. Perron MJ, Stremlau M, Lee M, Javanbakht H, Song B, Sodroski J. The human TRIM5 $\alpha$ restriction factor mediates accelerated uncoating of the N-tropic murine leukemia virus capsid. J Virol. (2007) 81:2138-48. doi: 10.1128/JVI.02318-06

141. Diaz-Griffero F, Qin X-R, Hayashi F, Kigawa T, Finzi A, Sarnak Z, et al. A B-box 2 surface patch important for TRIM5 $\alpha$ self-association, capsid binding avidity, and retrovirus restriction. J Virol. (2009) 83:10737-51. doi: 10.1128/JVI.01307-09

142. Langelier CR, Sandrin V, Eckert DM, Christensen DE, Chandrasekaran V, Alam SL, et al. Biochemical characterization of a recombinant TRIM5 $\alpha$ protein that restricts human immunodeficiency virus type 1 replication. $J$ Virol. (2008) 82:11682-94. doi: 10.1128/JVI.01562-08

143. Ganser-Pornillos BK, Chandrasekaran V, Pornillos O, Sodroski JG, Sundquist WI, Yeager M. Hexagonal assembly of a restricting TRIM5alpha protein. Proc Natl Acad Sci USA. (2011) 108:534-9. doi: $10.1073 /$ pnas. 1013426108

144. Wagner JM, Christensen DE, Bhattacharya A, Dawidziak DM, Roganowicz $\mathrm{MD}$, Wan Y, et al. A general model for retroviral capsid pattern recognition by TRIM5 proteins. J Virol. (2017) 92:e01563-17. doi: 10.1128/JVI.01563-17

145. Anderson JL, Campbell EM, Wu X, Vandegraaff N, Engelman A, Hope TJ. Proteasome inhibition reveals that a functional preintegration complex intermediate can be generated during restriction by diverse TRIM5 proteins. J Virol. (2006) 80:9754-60. doi: 10.1128/JVI.01052-06

146. Campbell EM, Perez O, Anderson JL, Hope TJ. Visualization of a proteasome-independent intermediate during restriction of HIV-1 by rhesus TRIM5alpha. J Cell Biol. (2008) 180:549-61. doi: 10.1083/jcb.200706154

147. Rold CJ, Aiken C. Proteasomal degradation of TRIM5 $\alpha$ inhibits during retrovirus restriction. PLoS Pathog. (2008) 4:e1000074. doi: 10.1371/journal.ppat.1000074

148. Wu X, Anderson JL, Campbell EM, Joseph AM, Hope TJ. Proteasome inhibitors uncouple rhesus TRIM5alpha restriction of HIV-1 reverse transcription and infection. Proc Natl Acad Sci USA. (2006) 103:7465-70. doi: 10.1073/pnas.0510483103

149. Pertel T, Hausmann S, Morger D, Züger S, Guerra J, Lascano J, et al. TRIM5 is an innate immune sensor for the retrovirus capsid lattice. Nature (2011) 472:361-5. doi: 10.1038/nature09976

150. Yudina Z, Roa A, Johnson R, Biris N, de Souza Aranha Vieira DA, Tsiperson V, et al. RING dimerization links higher-order assembly of
TRIM5 $\alpha$ to synthesis of K63-linked polyubiquitin. Cell Rep. (2015) 12:78897. doi: 10.1016/j.celrep.2015.06.072

151. Tareen SU, Emerman M. Human Trim $5 \alpha$ has additional activities that are uncoupled from retroviral capsid recognition. Virology (2011) 409:113-20. doi: 10.1016/j.virol.2010.09.018

152. Uchil PD, Hinz A, Siegel S, Coenen-Stass A, Pertel T, Luban J, et al. TRIM protein-mediated regulation of inflammatory and innate immune signaling and its association with antiretroviral activity. J Virol. (2013) 87:257-72. doi: 10.1128/JVI.01804-12

153. Versteeg GA, Benke S, García-Sastre A, Rajsbaum R. InTRIMsic immunity: positive and negative regulation of immune signaling by tripartite motif proteins. Cytokine Growth Factor Rev. (2014) 25:563-76. doi: 10.1016/j.cytogfr.2014.08.001

154. Versteeg GA, Rajsbaum R, Sánchez-Aparicio MTT, Maestre AMM, Valdiviezo J, Shi M, et al. The E3-ligase TRIM family of proteins regulates signaling pathways triggered by innate immune pattern-recognition receptors. Immunity (2013) 38:384-98. doi: 10.1016/j.immuni.2012. 11.013

155. Flajnik MF, Du Pasquier L. Evolution of innate and adaptive immunity: can we draw a line? Trends Immunol. (2004) 25:640-4. doi: 10.1016/j.it.2004.10.001

156. Choi UY, Hur JY, Lee MS, Zhang Q, Choi WY, Kim LK, et al. Tripartite motif-containing protein 30 modulates TCR-activated proliferation and effector functions in CD4+ T cells. PLoS ONE (2014) 9:e95805. doi: 10.1371/journal.pone.0095805

157. Jimenez-Moyano E, Ruiz A, Kløverpris HN, Rodriguez-Plata MT, Peña $\mathrm{R}$, Blondeau $\mathrm{C}$, et al. Nonhuman TRIM5 variants enhance recognition of HIV-1-infected cells by CD8 + T cells. J Virol. (2016) 90:8552-62. doi: 10.1128/JVI.00819-16

158. Jia R, Xu F, Qian J, Yao Y, Miao C, Zheng Y-M, et al. Identification of an endocytic signal essential for the antiviral action of IFITM3. Cell Microbiol. (2014) 16:1080-93. doi: 10.1111/cmi.12262

159. Li K, Jia R, Li M, Zheng YM, Miao C, Yao Y, et al. A sorting signal suppresses IFITM1 restriction of viral entry. J Biol Chem. (2015) 290:424859. doi: 10.1074/jbc.M114.630780

160. Stacey MA, Clare S, Clement M, Marsden M, Abdul-Karim J, Kane L, et al. The antiviral restriction factor IFN-induced transmembrane protein 3 prevents cytokine-driven CMV pathogenesis. J Clin Invest. (2017) 127:146374. doi: 10.1172/JCI84889

161. Wakim LM, Gupta N, Mintern JD, Villadangos JA. Enhanced survival of lung tissue-resident memory CD8 + T cells during infection with influenza virus due to selective expression of IFITM3. Nat Immunol. (2013) 14:238-45. doi: 10.1038/ni.2525

162. Roos-Mattjus P, Sistonen L. The ubiquitin-proteasome pathway. Ann Med. (2004) 36:285-95. doi: 10.1080/07853890310016324

163. Luo H. Interplay between the virus and the ubiquitin-proteasome system: molecular mechanism of viral pathogenesis. Curr Opin Virol. (2016) 17:1-10. doi: 10.1016/j.coviro.2015.09.005

164. Schubert U, Ott DE, Chertova EN, Welker R, Tessmer U, Princiotta MF, et al. Proteasome inhibition interferes with Gag polyprotein processing, release, and maturation of HIV-1 and HIV-2. Proc Natl Acad Sci USA. (2000) 97:2-7. doi: 10.1073/pnas.97.24.13057

165. Seissler T, Marquet R, Paillart J-C. Hijacking of the ubiquitin/proteasome pathway by the HIV auxiliary proteins. Viruses (2017) 9:322. doi: 10.3390/v9110322

166. Bour S, Perrin C, Akari H, Strebel K. The human immunodeficiency virus type $1 \mathrm{Vpu}$ protein inhibits NF-кB activation by interfering with $\beta$ TrCP-mediated degradation of IкB. J Biol Chem. (2001) 276:15920-8. doi: 10.1074/jbc.M010533200

167. Tobery TW, Siliciano RF. Targeting of HIV-1 antigens for rapid intracellular degradation enhances cytotoxic T lymphocyte (CTL) recognition and the induction of de novo CTL responses in vivo after immunization. J Exp Med. (1997) 185:909-20. doi: 10.1084/jem.185.5.909

168. Goldwich A, Hahn SSC, Schreiber S, Meier S, Kämpgen E, Wagner R, et al. Targeting HIV-1 Gag into the defective ribosomal product pathway enhances MHC class I antigen presentation and CD8+ T cell activation. J Immunol. (2008) 180:372-82. doi: 10.4049/jimmunol.180.1.372 
169. Champiat S, Garrison KE, Raposo RAS, Burwitz BJ, Reed J, Tandon R, et al. $\mathrm{T}$ cells target APOBEC 3 proteins in human immunodeficiency virus type 1infected humans and simian immunodeficiency virus-infected indian rhesus macaques. J Virol. (2013) 87:6073-80. doi: 10.1128/JVI.00579-12

170. Diaz-Griffero F, Li X, Javanbakht H, Song B, Welikala S, Stremlau M, et al. Rapid turnover and polyubiquitylation of the retroviral restriction factor TRIM5. Virology (2006) 349:300-15. doi: 10.1016/j.virol.2005.12.040

171. Danielson CM, Cianci GC, Hope TJ. Recruitment and dynamics of proteasome association with rhTRIM5 $\alpha$ cytoplasmic complexes during HIV1 infection. Traffic (2012) 13:1206-17. doi: 10.1111/j.1600-0854.2012.01381.x

172. Lukic Z, Hausmann S, Sebastian S, Rucci J, Sastri J, Robia SL, et al. TRIM5 $\alpha$ associates with proteasomal subunits in cells while in complex with HIV-1 virions. Retrovirology (2011) 8:93. doi: 10.1186/1742-4690-8-93

173. Grütter MG, Luban J. TRIM5 structure, HIV-1 capsid recognition, and innate immune signaling. Curr Opin Virol. (2012) 2:142-50. doi: 10.1016/j.coviro.2012.02.003

174. Setz C, Friedrich M, Rauch P, Fraedrich K, Matthaei A, Traxdorf M, et al. Inhibitors of deubiquitinating enzymes block HIV-1 replication and augment the presentation of gag-derived MHC-I epitopes. Viruses (2017) 9:1-22. doi: 10.3390/v9080222

175. Fletcher AJ, Mallery DL, Watkinson RE, Dickson CF, James LC. Sequential ubiquitination and deubiquitination enzymes synchronize the dual sensor and effector functions of TRIM21. Proc Natl Acad Sci USA. (2015) 112:10014-19. doi: 10.1073/pnas.1507534112

176. Fletcher AJ, Christensen DE, Nelson C, Tan CP, Schaller T, Lehner $\mathrm{PJ}$, et al. TRIM5 $\alpha$ requires Ube2W to anchor Lys63-linked ubiquitin chains and restrict reverse transcription. EMBO J. (2015) 34:1-18. doi: $10.15252 / \mathrm{embj} .201490361$

177. Münz C. Enhancing immunity through autophagy. Annu Rev Immunol. (2009) 27:423-49. doi: 10.1146/annurev.immunol.021908.132537

178. Deretic V. Autophagy: an emerging immunological paradigm. J Immunol. (2012) 189:15-20. doi: 10.4049/jimmunol.1102108

179. Kuballa P, Nolte WM, Castoreno AB, Xavier RJ. Autophagy and the immune system. Annu Rev Immunol. (2012) 30:611-46. doi: 10.1146/annurev-immunol-020711-074948

180. Shibutani ST, Saitoh T, Nowag H, Münz C, Yoshimori T. Autophagy and autophagy-related proteins in the immune system. Nat Immunol. (2015) 16:1014-24. doi: 10.1038/ni.3273

181. Takahama M, Akira S, Saitoh T. Autophagy limits activation of the inflammasomes. Immunol Rev. (2018) 281:62-73. doi: 10.1111/imr.12613

182. Münz C. Autophagy beyond intracellular MHC class II antigen presentation. Trends Immunol. (2016) 37:755-63. doi: 10.1016/j.it.2016.08.017

183. Schmid D, Pypaert M, Münz C. Antigen-loading compartments for major histocompatibility complex class II molecules continuously receive input from autophagosomes. Immunity (2007) 26:79-92. doi: 10.1016/j.immuni.2006.10.018

184. Paludan C, Schmid D, Landthaler M, Vockerodt M, Kube D, Tuschl T, et al. Endogenous MHC class II processing of a viral nuclear antigen after autophagy. Science (2005) 307:593-6. doi: 10.1126/science.1104904

185. English L, Chemali M, Duron J, Rondeau C, Laplante A, Gingras D, et al. Autophagy enhances the presentation of endogenous viral antigens on MHC class I molecules during HSV-1 infection. Nat Immunol. (2009) 10:1-18. doi: $10.1038 /$ ni. 1720

186. Tey S, Khanna R. Autophagy mediates transporter associated with antigen processing-independent presentation of viral epitopes through MHC class I pathway. Blood (2012) 120:994-1004. doi: 10.1182/blood-2012-01402404

187. Van Kaer L, Parekh VV, Postoak JL, Wu L. Role of autophagy in MHC class I-restricted antigen presentation. Mol Immunol. (2017). doi: 10.1016/j.molimm.2017.10.021. [Epub ahead of print].

188. Keller CW, Loi M, Ligeon LA, Gannagé M, Lünemann JD, Münz C. Endocytosis regulation by autophagy proteins in MHC restricted antigen presentation. Curr Opin Immunol. (2018) 52:68-73. doi: 10.1016/j.coi.2018.04.014

189. Sparrer KMJ, Gack MU. TRIM proteins: new players in virus-induced autophagy. PLoS Pathog. (2018) 14:e1006787. doi: 10.1371/journal.ppat.1006787
190. Sparrer KMJ, Gableske S, Zurenski MA, Parker ZM, Full F, Baumgart GJ, et al. TRIM23 mediates virus-induced autophagy via activation of TBK1. Nat Microbiol. (2017) 2:1543-57. doi: 10.1038/s41564-017-0017-2

191. O'Connor C, Pertel T, Gray S, Robia SL, Bakowska JC, Luban J, et al. p62/sequestosome-1 associates with and sustains the expression of retroviral restriction factor TRIM5 $\alpha$. J Virol. (2010) 84:5997-6006. doi: 10.1128/JVI.02412-09

192. Mandell MA, Jain A, Arko-Mensah J, Chauhan S, Kimura T, Dinkins C, et al. TRIM proteins regulate autophagy and can target autophagic substrates by direct recognition. Dev Cell (2014) 30:394-409. doi: 10.1016/j.devcel.2014.06.013

193. Kimura T, Jain A, Choi SW, Mandell MA, Johansen T, Deretic V. TRIMdirected selective autophagy regulates immune activation. Autophagy (2017) 13:989-90. doi: 10.1080/15548627.2016.1154254

194. Blanchet FP, Moris A, Nikolic DS, Lehmann M, Cardinaud S, Stalder R, et al. Human immunodeficiency virus-1 inhibition of immunoamphisomes in dendritic cells impairs early innate and adaptive immune responses. Immunity (2010) 32:654-69. doi: 10.1016/j.immuni.2010.04.011

195. Coulon P-G, Richetta C, Rouers A, Blanchet FP, Urrutia A, Guerbois M, et al. HIV-infected dendritic cells present endogenous MHC class II-restricted antigens to HIV-specific CD4 ${ }^{+}$T cells. J Immunol. (2016) 197:517-32. doi: 10.4049/jimmunol.1600286

196. Imam S, Talley S, Nelson RS, Dharan A, O'Connor C, Hope TJ, et al. TRIM $5 \alpha$ degradation via autophagy is not required for retroviral restriction. $J$ Virol. (2016) 90:3400-10. doi: 10.1128/JVI.03033-15

197. Park C, Cuervo AM. Selective autophagy: talking with the UPS. Cell Biochem Biophys. (2013) 67:3-13. doi: 10.1007/s12013-013-9623-7

198. Korolchuk VI, Menzies FM, Rubinsztein DC. Mechanisms of crosstalk between the ubiquitin-proteasome and autophagy-lysosome systems. FEBS Lett. (2010) 584:1393-8. doi: 10.1016/j.febslet.2009. 12.047

199. Jongsma MLLM, Berlin I, Wijdeven RHHM, Janssen L, Janssen GMMC, Garstka MAA, et al. An ER-associated pathway defines endosomal architecture for controlled cargo transport. Cell (2016) 166:152-66. doi: 10.1016/j.cell.2016.05.078

200. Katzmann DJ, Babst M, Emr SD. Ubiquitin-dependent sorting into the multivesicular body pathway requires the function of a conserved endosomal protein sorting complex, ESCRT-I. Cell (2001) 106:145-55. doi: 10.1016/S0092-8674(01)00434-2

201. Clague MJ, Urbé S. Ubiquitin: same molecule, different degradation pathways. Cell (2010) 143:682-5. doi: 10.1016/j.cell.2010.11.012

202. Jolly C, Booth NJ, Neil SJD. Cell-cell spread of human immunodeficiency virus type 1 overcomes tetherin/BST-2-mediated restriction in T cells. J Virol. (2010) 84:12185-99. doi: 10.1128/JVI.01447-10

203. Casartelli N, Sourisseau M, Feldmann J, Guivel-Benhassine F, Mallet A, Marcelin A-G, et al. Tetherin restricts productive HIV-1 cell-to-cell transmission. PLoS Pathog. (2010) 6:e1000955. doi: 10.1371/journal.ppat.1000955

204. Kuhl BD, Sloan RD, Donahue DA, Bar-Magen T, Liang C, Wainberg MA. Tetherin restricts direct cell-to-cell infection of HIV-1. Retrovirology (2010) 7:115. doi: 10.1186/1742-4690-7-115

205. Rollason R, Korolchuk V, Hamilton C, Schu P, Banting G. Clathrin-mediated endocytosis of a lipid-raft-associated protein is mediated through a dual tyrosine motif. J Cell Sci. (2007) 120:3850-8. doi: 10.1242/jcs.003343

206. Moris A, Pajot A, Blanchet F, Guivel-benhassine F, Salcedo M, Schwartz O. Dendritic cells and HIV-specific CD4+ $\mathrm{T}$ cells: HIV antigen presentation, T-cell activation, and viral transfer. Blood (2006) 108:1643-51. doi: 10.1182/blood-2006-02-006361

207. Li SX, Barret Badley S, Guo K, Santiago ML. Tetherin/BST-2: restriction factor or immunomodulator? Curr HIV Res. (2016) 14:235-46. doi: 10.2174/1570162X14999160224102752

208. Davey RT Jr, Bhat N, Yoder C, Chun TW, Metcalf JA, Dewar R, et al. HIV-1 and $\mathrm{T}$ cell dynamics after interruption of highly active antiretroviral therapy (HAART) in patients with a history of sustained viral suppression. Proc Natl Acad Sci USA. (1999) 96:15109-14. doi: 10.1073/pnas.96.26.15109

209. Chun T-W, Davey RT Jr, Engel D, Lane HC, Fauci AS. Re-emergence of HIV after stopping therapy. Nature (1999) 401:874-5. doi: 10.1038/44755 
210. Argyris EG, Acheampong E, Wang F, Huang J, Chen K, Mukhtar M, et al. The interferon-induced expression of APOBEC $3 \mathrm{G}$ in human blood-brain barrier exerts a potent intrinsic immunity to block HIV-1 entry to central nervous system. Virology (2007) 367:440-51. doi: 10.1016/j.virol.2007.06.010

211. Wang FX, Huang J, Zhang H, Ma X, Zhang H. APOBEC3G upregulation by alpha interferon restricts human immunodeficiency virus type 1 infection in human peripheral plasmacytoid dendritic cells. J Gen Virol. (2008) 89:72230. doi: 10.1099/vir.0.83530-0

212. Mohanram V, Skold AE, Bachle SM, Pathak SK, Spetz A-L. IFN$\alpha$ induces APOBEC3G, F, and $\mathrm{A}$ in immature dendritic dells and limits HIV-1 spread to CD4+ T cells. J Immunol. (2013) 190:3346-53. doi: 10.4049/jimmunol.1201184

213. Homann S, Smith D, Little S, Richman D, Guatelli J. Upregulation of BST-2/tetherin by HIV infection in vivo. J Virol. (2011) 85:10659-68. doi: 10.1128/JVI.05524-11

214. Riess M, Fuchs NV, Idica A, Hamdorf M, Flory E, Pedersen IM, et al. Interferons induce expression of SAMHD1 in monocytes through downregulation of miR-181a and miR-30a. J Biol Chem. (2017) 292:264-77. doi: 10.1074/jbc.M116.752584

215. Chen Z, Zhang L, Ying S. SAMHD1: a novel antiviral factor in intrinsic immunity. Future Microbiol. (2012) 7:1117-26. doi: 10.2217/fmb.12.81

216. St Gelais C, de Silva S, Amie SM, Coleman CM, Hoy H, Hollenbaugh JA, et al. SAMHD1 restricts HIV-1 infection in dendritic cells (DCs) by dNTP depletion, but its expression in DCs and primary CD4+ Tlymphocytes cannot be upregulated by interferons. Retrovirology (2012) 9:1-15. doi: 10.1186/1742-4690-9-105

217. Sakuma R, Mael AA, Ikeda Y. Alpha interferon enhances TRIM5 $\alpha$-mediated antiviral activities in human and rhesus monkey cells. J Virol. (2007) 81:10201-6. doi: 10.1128/JVI.00419-07

218. Tavel JA, Huang C-Y, Shen J, Metcalf JA, Dewar R, Shah A, et al. Interferon$\alpha$ produces significant decreases in HIV load. J Interf Cytokine Res. (2010) 30:461-4. doi: 10.1089/jir.2009.0090

219. Sandler NG, Bosinger SE, Estes JD, Zhu RTR, Tharp GK, Boritz E, et al. Type I interferon responses in rhesus macaques prevent SIV infection and slow disease progression. Nature (2014) 511:601-5. doi: 10.1038/nature13554

220. Pillai SK, Abdel-Mohsen M, Guatelli J, Skasko M, Monto A, Fujimoto $\mathrm{K}$, et al. Role of retroviral restriction factors in the interferon- $\alpha$-mediated suppression of HIV-1 in vivo. Proc Natl Acad Sci USA. (2012) 109:3035-40. doi: 10.1073/pnas.1111573109

221. Abdel-Mohsen M, Deng X, Liegler T, Guatelli JC, Salama MS, Ghanem HE$\mathrm{d}$ A, et al. Effects of alpha interferon treatment on intrinsic anti-HIV-1 immunity in vivo. J Virol. (2014) 88:763-7. doi: 10.1128/JVI.02687-13

222. Lavender KJ, Gibbert K, Peterson KE, Van Dis E, Francois S, Woods T, et al. Interferon alpha subtype-specific suppression of HIV-1 infection in vivo. J Virol. (2016) 90:6001-13. doi: 10.1128/JVI.00451-16

223. Wang B, Kang W, Zuo J, Kang W, Sun Y. The significance of type-I interferons in the pathogenesis and therapy of human immunodeficiency virus 1 infection. Front Immunol. (2017) 8:1-12. doi: 10.3389/fimmu.2017.01431

224. Bennett RP, Salter JD, Smith HC. A new class of antiretroviral enabling innate immunity by protecting APOBEC3 from HIV Vif-dependent degradation. Trends Mol Med. (2018) 24:507-20. doi: 10.1016/j.molmed.2018.03.004

225. Mi Z, Ding J, Zhang Q, Zhao J, Ma L, Yu H, et al. A small molecule compound IMB-LA inhibits HIV-1 infection by preventing viral Vpu from antagonizing the host restriction factor BST-2. Sci Rep. (2015) 5:1-13. doi: 10.1038/srep18499

226. Reingewertz TH, Britan-Rosich E, Rotem-Bamberger S, Viard M, Jacobs A, Miller A, et al. Mapping the Vif-A3G interaction using peptide arrays: a basis for anti-HIV lead peptides. Bioorganic Med Chem. (2013) 21:3523-32. doi: 10.1016/j.bmc.2013.03.001

227. Rosenberg MR, Weaver LM, Casarotto MG. Probing interactions of Vpu from HIV-1 with amiloride-based compounds. Biochim Biophys Acta (2016) 1858:733-9. doi: 10.1016/j.bbamem.2015.12.028

228. Pery E, Sheehy A, Nebane NM, Brazier AJ, Misra V, Rajendran KS, et al. Identification of a novel HIV-1 inhibitor targeting Vif-dependent degradation of human APOBEC3G protein. J Biol Chem. (2015) 290:1050417. doi: $10.1074 /$ jbc.M114.626903
229. Cen S, Peng ZG, Li XY, Li ZR, Ma J, Wang YM, et al. Small molecular compounds inhibit HIV-1 replication through specifically stabilizing APOBEC3G. J Biol Chem. (2010) 285:16546-52. doi: 10.1074/jbc.M109.085308

230. Miyakawa K, Matsunaga S, Kanou K, Matsuzawa A, Morishita R, Kudoh A, et al. ASK1 restores the antiviral activity of APOBEC3G by disrupting HIV-1 Vif-mediated counteraction. Nat Commun. (2015) 6:6945. doi: 10.1038/ncomms7945

231. Zhang S, Zhong L, Chen B, Pan T, Zhang X, Liang L, et al. Identification of an HIV-1 replication inhibitor which rescues host restriction factor APOBEC3G in Vif-APOBEC3G complex. Antiviral Res. (2015) 122:20-7. doi: 10.1016/j.antiviral.2015.07.009

232. Zuo T, Liu D, Lv W, Wang X, Wang J, Lv M, et al. Small-molecule inhibition of human immunodeficiency virus type 1 replication by targeting the interaction between Vif and ElonginC. J Virol. (2012) 86:5497-507. doi: 10.1128/JVI.06957-11

233. Bolduan S, Votteler J, Lodermeyer V, Greiner T, Koppensteiner H, Schindler $\mathrm{M}$, et al. Ion channel activity of HIV-1 Vpu is dispensable for counteraction of CD317. Virology (2011) 416:75-85. doi: 10.1016/j.virol.2011.04.009

234. Bour S, Strebel K. The HIV-1 Vpu protein: a multifunctional enhancer of viral particle release. Microbes Infect. (2003) 5:1029-39. doi: 10.1016/S1286-4579(03)00191-6

235. Schubert U, Ferrer-Montiel AV, Oblatt-Montal M, Henklein P, Strebel $\mathrm{K}$, Montal M. Identification of an ion channel activity of the Vpu transmembrane domain and its involvement in the regulation of virus release from HIV-1-infected cells. FEBS Lett. (1996) 398:12-8. doi: 10.1016/S0014-5793(96)01146-5

236. Park SH, Opella SJ. Conformational changes induced by a single amino acid substitution in the trans -membrane domain of Vpu: implications for HIV1 susceptibility to channel blocking drugs. Protein Sci. (2007) 16:2205-15. doi: 10.1110/ps.073041107

237. Baldauf H-M, Pan X, Erikson E, Schmidt S, Daddacha W, Burggraf M, et al. SAMHD1 restricts HIV-1 infection in resting CD4+ T cells. Nat Med. (2012) 18:1682-9. doi: 10.1038/nm.2964

238. Wu L. SAMHD1: a new contributor to HIV-1 restriction in resting CD4+ T-cells. Retrovirology (2012) 9:88. doi: 10.1186/1742-4690-9-88

239. Hollenbaugh JA, Shelton J, Tao S, Amiralaei S, Liu P, Lu X, et al. Substrates and inhibitors of SAMHD1. PLOS ONE (2017) 12:e169052. doi: 10.1371/journal.pone.0169052

240. Szaniawski MA, Spivak AM, Cox JE, Catrow JL, Hanley T, Williams ESCP, et al. SAMHD1 phosphorylation coordinates the anti-HIV-1 response by diverse interferons and tyrosine kinase inhibition. MBio (2018) 9:1-14. doi: 10.1128/mBio.00819-18

241. Badia R, Angulo G, Riveira-Muñoz E, Pujantell M, Puig T, Ramirez C, et al. Inhibition of herpes simplex virus type 1 by the CDK6 inhibitor PD-0332991 (palbociclib) through the control of SAMHD1. J Antimicrob Chemother. (2016) 71:387-94. doi: 10.1093/jac/dkv363

242. Schor S, Einav S. Repurposing of kinase inhibitors as broad-spectrum antiviral drugs. DNA Cell Biol. (2018) 37:63-9. doi: 10.1089/dna.2017.4033

243. Pauls E, Badia R, Torres-Torronteras J, Ruiz A, Permanyer M, RiveiraMuñoz E, et al. Palbociclib, a selective inhibitor of cyclin-dependent kinase4/6, blocks HIV-1 reverse transcription through the control of sterile a motif and HD domain-containing protein-1 (SAMHD1) activity. AIDS (2014) 28:2213-22. doi: 10.1097/QAD.00000000000 00399

244. Bermejo M, López-Huertas MR, Hedgpeth J, Mateos E, Rodríguez-Mora $\mathrm{S}$, Maleno MJ, et al. Analysis of protein kinase $\mathrm{C}$ theta inhibitors for the control of HIV-1 replication in human CD4+ T cells reveals an effect on retrotranscription in addition to viral transcription. Biochem Pharmacol. (2015) 94:241-56. doi: 10.1016/j.bcp.2015.02.009

245. Mlcochova P, Caswell SJ, Taylor IA, Towers GJ, Gupta RK. DNA damage induced by topoisomerase inhibitors activates SAMHD1 and blocks HIV-1 infection of macrophages. EMBO J. (2017) 37:50-62. doi: 10.15252/embj.201796880

246. Yap MW, Mortuza GB, Taylor IA, Stoye JP. The design of artificial retroviral restriction factors. Virology (2007) 365:302-14. doi: 10.1016/j.virol.2007.04.005 
247. Thenin-Houssier S, Valente ST. HIV-1 capsid inhibitors as antiretroviral agents. Curr HIV Res. (2016) 14:270-82. doi: 10.2174/1570162X14999160224103555

248. Santa-Marta M, de Brito PM, Godinho-Santos A, Goncalves J. Host factors and HIV-1 replication: clinical evidence and potential therapeutic approaches. Front Immunol. (2013) 4:1-20. doi: 10.3389/fimmu.2013.00343

249. Stopak K, De Noronha C, Yonemoto W, Greene WC. HIV-1 Vif blocks the antiviral activity of APOBEC3G by impairing both its translation and intracellular stability. Mol Cell (2003) 12:591-601. doi: 10.1016/S1097-2765(03)00353-8

250. McNatt MW, Zang T, Bieniasz PD. Vpu binds directly to tetherin and displaces it from nascent virions. PLoS Pathog. (2013) 9:e1003299. doi: 10.1371/journal.ppat.1003299

251. Chan E, Towers GJ, Qasim W. Gene therapy strategies to exploit TRIM derived restriction factors against HIV-1. Viruses (2014) 6:243-63. doi: 10.3390/v6010243

252. Li Y, Li X, Stremlau M, Lee M, Sodroski J. Removal of arginine 332 allows human TRIM5alpha to bind human immunodeficiency virus capsids and to restrict infection. J Virol. (2006) 80:6738-44. doi: 10.1128/JVI.00270-06

253. Pham Q, Bouchard A, Grütter M, Berthoux L. Generation of human TRIM $5 \alpha$ mutants with high HIV-1 restriction activity. Gene Ther. (2010) 17:859-71. doi: $10.1038 /$ gt.2010.40

254. Jung U, Urak K, Veillette M, Nepveu-Traversy M-É, Pham QT, Hamel S, et al. Preclinical assessment of mutant human TRIM5 $\alpha$ as an anti-HIV-1 transgene. Hum Gene Ther. (2015) 26:664-79. doi: 10.1089/hum.2015.059

255. Richardson MW, Guo L, Xin F, Yang X, Riley JL. Stabilized human TRIM5 $\alpha$ protects human T cells from HIV-1 infection. Mol Ther. (2014) 22:1084-95. doi: $10.1038 / \mathrm{mt} .2014 .52$

256. Anderson J, Akkina R. Human immunodeficiency virus type 1 restriction by human-rhesus chimeric tripartite motif 5alpha (TRIM5alpha) in CD34 $(+)$ cell-derived macrophages in vitro and in T cells in vivo in severe combined immunodeficient (SCID-hu) mice transplanted with human fetal tissue. Hum Gene Ther. (2008) 19:217-28. doi: 10.1089/hum.2007.108

257. Nisole S, Lynch C, Stoye JP, Yap MW. A Trim5-cyclophilin A fusion protein found in owl monkey kidney cells can restrict HIV-1. Proc Natl Acad Sci USA. (2004) 101:13324-8. doi: 10.1073/pnas.0404640101
258. Neagu MR, Ziegler P, Pertel T, Strambio-De-Castillia C, Grütter C, Martinetti $\mathrm{G}$, et al. Potent inhibition of HIV-1 by TRIM5-cyclophilin fusion proteins engineered from human components. J Clin Invest. (2009) 119:3035-47. doi: 10.1172/JCI39354

259. Chan E, Schaller T, Eddaoudi A, Zhan H, Tan CP, Jacobsen M, et al. Lentiviral gene therapy against human immunodeficiency virus type 1, using a novel human TRIM21-cyclophilin A restriction factor. Hum Gene Ther. (2012) 23:1176-85. doi: 10.1089/hum.2012.083

260. Anderson JS, Javien J, Nolta JA, Bauer G. Preintegration HIV-1 inhibition by a combination lentiviral vector containing a chimeric TRIM5 alpha protein, a CCR5 shRNA, and a TAR decoy. Mol Ther. (2009) 17:2103-14. doi: $10.1038 / \mathrm{mt} .2009 .187$

261. Walker JE, Chen RX, McGee J, Nacey C, Pollard RB, Abedi M, et al. Generation of an HIV-1-resistant immune system with CD34+ hematopoietic stem cells transduced with a triple-combination antiHIV lentiviral vector. J Virol. (2012) 86:5719-29. doi: 10.1128/JVI. 06300-11

262. Weatherley DAV, Boswell MT, Rowland-Jones SL. Targeting TRIM5 $\alpha$ in HIV cure strategies for the CRISPR-Cas9 era. Front Immunol. (2017) 8:1616. doi: 10.3389/fimmu.2017.01616

263. Dufour C, Claudel A, Joubarne N, Merindol N, Maisonnet T, Masroori $\mathrm{N}$, et al. Editing of the human TRIM5 gene to introduce mutations with the potential to inhibit HIV-1. PLOS ONE (2018) 13:e0191709. doi: 10.1371/journal.pone.0191709

Conflict of Interest Statement: The authors declare that the research was conducted in the absence of any commercial or financial relationships that could be construed as a potential conflict of interest.

Copyright (C) 2018 Colomer-Lluch, Ruiz, Moris and Prado. This is an open-access article distributed under the terms of the Creative Commons Attribution License (CC BY). The use, distribution or reproduction in other forums is permitted, provided the original author(s) and the copyright owner(s) are credited and that the original publication in this journal is cited, in accordance with accepted academic practice. No use, distribution or reproduction is permitted which does not comply with these terms. 